\title{
Transformaciones morfosedimentarias de la bahía estuarina de Santander relacionadas con el desarrollo portuario y urbano (Cantabria, NO de España)
}

\section{Morphosedimentary transformations of the Santander estuarine bay related to port and urban development (Cantabria, NW Spain)}

\author{
GERMÁn Flor ${ }^{\mathrm{I}}$ y Germán Flor-BlanCO ${ }^{\mathrm{I}}$ \\ ${ }^{1}$ Departamento de Geología, Universidad de Oviedo, Cl Jesús Arias de Velasco s/n, 33005 Oviedo, España. \\ Grupo de investigación GeoQUO (Geomorfología y Cuaternario, Universidad de Oviedo) \\ (e-mail: gflor@geol.uniovi.es, gfb@geol.uniovi.es)
}

\begin{abstract}
Resumen: En el amplio complejo de la Bahía de Santander, coexisten dos subsistemas estuarinos muy contrastados. Numerosas transformaciones tuvieron lugar como consecuencia del desarrollo del gran puerto comercial y el crecimiento de la ciudad de Santander. Especialmente, las marismas fueron desnaturalizadas y se practicaron rellenos artificiales de forma mayoritaria en la margen occidental con la consiguiente reducción de espacios activos. Asimismo, se practicaron dragados intensos de manera particular en el canal principal que, a su vez, eliminaron el delta mareal de flujo, el paso y la barra de desembocadura. Estas prácticas, junto con los dragados de mantenimiento necesarios, han repercutido en fechas posteriores sobre la evolución de la espiga confinante de Somo-El Puntal, que experimenta un crecimiento longitudinal de varios cientos de metros hacia el $\mathrm{O}$ y un estrechamiento paulatino. Se cartografiaron las principales unidades morfosedimentarias desde la reconstrucción original previa de mediados de siglo xix en que se iniciaron las mayores transformaciones, considerando los hitos principales representativos desde 1956 hasta 2015. Se evidencian las ocupaciones paulatinas del margen occidental del subsistema de Santander por el puerto y la ciudad, el crecimiento de la espiga de Somo-El Puntal y la colonización vegetal del campo dunar culminante y los escasos rellenos del subsistema de Cubas, así como la fijación del canal de navegación en este último.
\end{abstract}

Palabras clave: subsistemas estuarinos, unidades morfosedimentarias, cartografía, dragados, evolución histórica, Santander. 


\begin{abstract}
In the broad Bay of Santander, there are included two very contrasting estuarine subsystems. Many changes took place as a result of the development of large commercial port and urbanizing progressively of Santander city. Especially, marshes were reclaimed and have been covered by artificial fill in the western areas, and the consequent reduction in active spaces. Also the main navigation channel was intense dredged, and flood-tide delta, inlet and mouth bar were fully removed. These dredging activities subsequently had repercussions on the evolution of the SomoEl Puntal spit, which undergoes a longitudinal growth of several hundred meters to the W and a gradual narrowing. The main morpho-sedimentary units are mapped since the original distribution of mid-nineteenth century when major changes were initiated considering the major milestones representative from 1956 to 2015. Gradual occupation of the western marshes of the Santander subsystem, Somo-El Puntal spit migration and vegetal colonization of its dune field are evidenced as well as the scarce filling of the Cubas subsystem, where the navigation channel was fixed.
\end{abstract}

Keywords: estuarine subsystems, morphosedimentary units, mapping, dredging, historical development, Santander.

A lo largo de más de un siglo son numerosos los ejemplos de modificación humana en los estuarios y la costa en general, donde se han aplicado soluciones ingenieriles (Halouani et al., 2012). La mayor parte de las variaciones están relacionadas con la alteración de los canales de navegación en la bocana mediante estructuras rígidas (Haupt, 1888, Flemming et al., 2000; Rodríguez-Ramírez et al. 2008; Flor-Blanco et al., 2015a) que, debido a la anchura y calados escasos de la bocana, se ha optado por dragarlos intensivamente. Otras intervenciones han consistido en la ocupación de gran parte de la superficie de la bahía y las marismas para poder así incrementar las superficies portuarias, urbanas, industriales, así como la construcción del aeropuerto de Parayas de Santander. Se han producido avances de la línea de estas superficies buscando la proximidad al canal, así como la construcción de muelles rígidos que garantizaran los calados suficientes de los atraques.

Numerosos estudios han abordado la problemática de la gestión de los dragados y vertidos de los sedimentos de los puertos (National Research Council, Marine Board, 1985; Rodrigue, 2004; Cearreta et al., 2008; Flor-Blanco et al., 2013, Van Maren et al., 2015), incluso en sistemas costeros similares de la costa cantábrica. Se han realizado dragados de mantenimiento con gestiones más o menos acertadas, que, generalmente, han producido el retroceso de los campos dunares a causa de decisiones incorrectas en cuanto a los vertidos de los dragados llevados a cabo en las bocanas. Ejemplos de gestión, como son los casos del Nalón (Flor-Blanco et al., 2013; Flor-Blanco et al., 2015a) y Villaviciosa en Asturias (Flor et al., 2015) y San Vicente de la Barquera en Cantabria (Flor-Blanco et al., 2015b), están relacionados con estuarios cuyas bocanas han sido modificadas con la construcción de estructuras rígidas, que se prolongaron mar afuera, migrando la barrera confinante, pero cuyos fondos siguen requiriendo un mantenimiento de los calados de las entradas.

La zona de estudio está situada en la parte norte-central de la Península Ibérica (Fig. 1), concretamente en el mar Cantábrico. Tanto la ciudad de Santander como su puerto se han desarrollado en la margen occidental de la bahía (Fig. 2), donde se promovieron alteraciones intensas con cambios en los usos del suelo (desnaturalización de marismas y otros ambientes morfodinámicos), rellenos artificiales avanzando hacia el canal principal, y antropización de márgenes y dragados. También se ha intervenido directamente sobre la flecha arenosa de Somo-El Puntal, rellenando y vegetando los numerosos pasillos de tormentas para la fijación de las dunas, incluyendo la plantación de especies vegetales autóctonas; esta barrera, que confina la bahía, ha experimentado, indirectamente, una progradación longitudinal, así como el estrechamiento por los temporales de los últimos años (Losada et al., 1991; APs, 2012b; Borghero, 2015).

El objetivo de este trabajo reside en mostrar los cambios morfosedimentarios acaecidos en el sector 

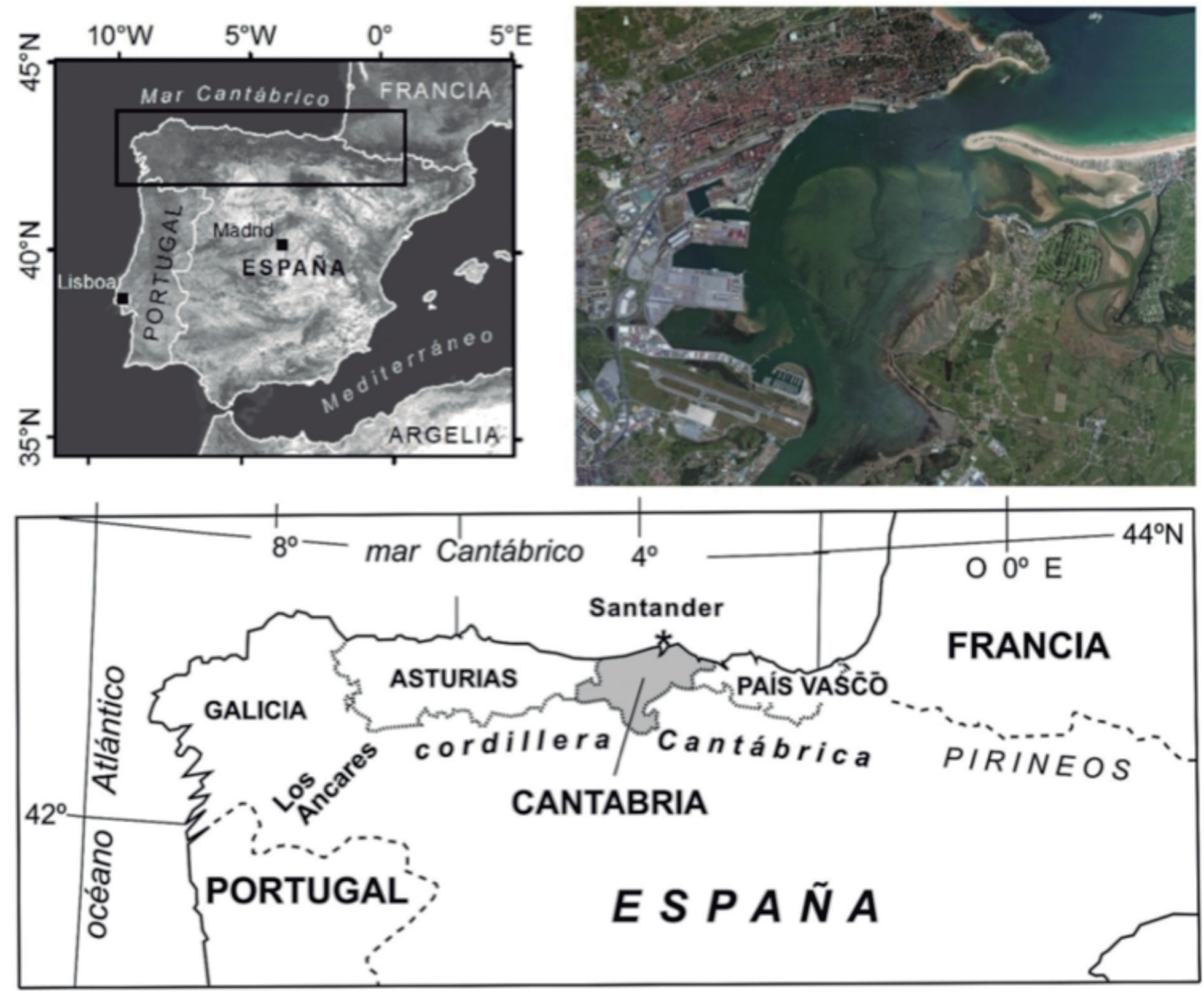

Figura 1. Situación de la bahía de Santander en el contexto de la Península Ibérica dentro del área septentrional costera (mar Cantábrico). Perspectiva en vertical de 2015 a partir de la imagen satelital más reciente de Bing Maps.

externo del estuario de Santander, mediante la interpretación de mapas topográficos antiguos y diversas series fotográficas históricas hasta la actualidad con la consiguiente cartografía detallada de las unidades representativas. Se trata de detallar la evolución en la desembocadura, bahía y marismas de la bahía de Santander a causa de la ocupación humana y la gestión portuaria implícita, conllevando variaciones en las distintas unidades morfológicas y la distribución sedimentaria, y, además, teniendo en cuenta las pautas de comportamiento por la paulatina subida del nivel del mar.

\section{Configuración general}

La bahía de Santander forma parte del área costera centro occidental de la Comunidad Autónoma de
Cantabria (Fig. 1), donde se asienta la capital como centro de desarrollo administrativo y comercial de la región. Parte del entorno se ha catalogado como Lugar de Interés Comunitario «Dunas del Puntal y estuario del Miera» (LIC ES1300005), que incluye la desembocadura del río Miera (ría de Cubas) y las Dunas del Puntal de Somo-Loredo y las islas de Santa Marina y de Mouro (Ley de Cantabria de 4/2006 de 19 de mayo).

La bahía de Santander está constituida por dos subsistemas estuarinos de dimensiones muy contrastadas (Santander, propiamente dicho, y Cubas), cuyas unidades morfosedimentarias y dinámicas son muy diferentes y variadas. Se confina por una única espiga arenosa (Somo-El Puntal) de $2700 \mathrm{~m}$ de longitud y anchuras variables de 100 a $250 \mathrm{~m}$, que se continúa hacia el E por otros $2175 \mathrm{~m}$, representada por la 


\section{Subsistema estuarinos}

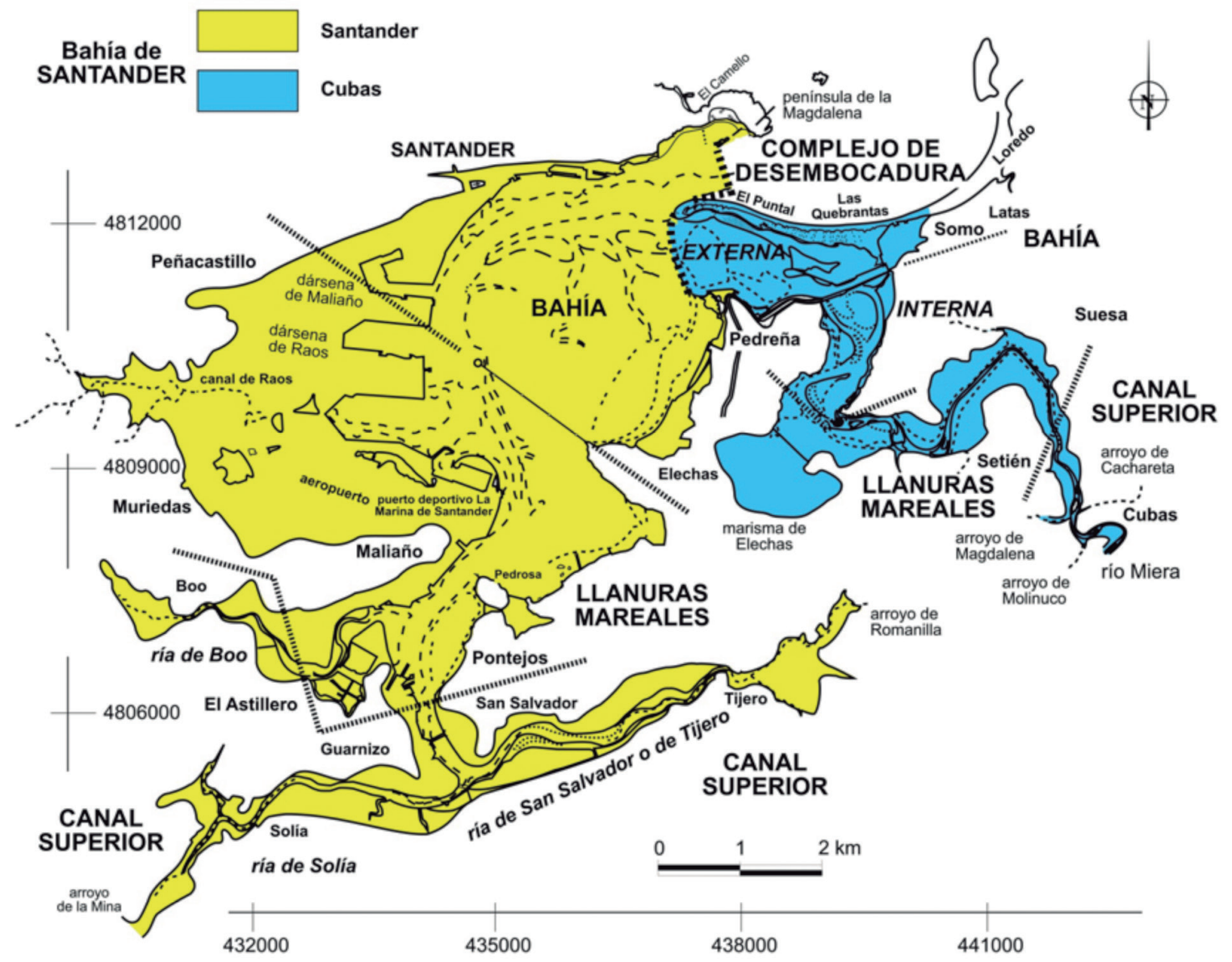

Figura 2. Zonaciones geomorfológicas principales de los dos subsistemas estuarinos de la bahía de Santander, el de Santander de mayor amplitud (fondo amarillo) y el oriental de Cubas en fondo azulado (modificado de Flor y Flor-Blanco, 2014a).

playa apoyada de Loredo, que se arquea en concha hasta su extremo NE (Fig. 2). Ambos subsistemas se conectan insensiblemente en las áreas más externas, justo desde la punta Rabiosa de la espiga de Somo-El Puntal (complejo de desembocadura del subsistema de Santander) hasta la punta del Rostro en el extremo occidental de la localidad de Pedreña (bahía externa del subsistema de Cubas), el cual desarrolla, además, una zona de bahía arenosa interna (Fig. 2).

El río Miera constituye el eje fluvial principal, que se encaja desde la divisoria hidrográfica de la cordillera Cantábrica, drenando al subsistema de Cubas. Este subsistema estuarino está representado por un relleno sedimentario de meandros encajados, marcando una planta sinuosa que se orienta preferentemente NO-SE. En el río Miera, el escaso volumen de agua dulce, que se mezcla con el voluminoso prisma de agua salada, determina que las mezclas de aguas sean típicas de un estuario verticalmente homogéneo.

Por el contrario, el subsistema de Santander está drenado por un conjunto de ríos y arroyos costeros con una superficie total de cuenca de $98,94 \mathrm{~km}^{2}$, en lo que constituye un subsistema de mucha mayor magnitud que el del Cubas (Fig. 2). Existen tres arroyos tributarios en la cola estuarina meridional, denominados como rías de Boo o del Carmen, Solía y San Salvador o Tijero (Fig. 2), que condicionan salinidades medias de mezcla, variables entre 29,3 y $38,6 \%$, rebajándose en las conexiones con los sistemas fluviales (Echavarri et al., 2007), con un marcado cambio estacional (Moreno-Ventas, 1998). Este subsistema está constituido por cuatro zonas geomorfológicas mayores (Flor y Flor-Blanco, 2014a) que, hacia el interior estuarino, son: complejo de desembocadura, 
bahía, llanuras mareales y canal superior, mientras que el de Cubas se reduce a una bahía que desarrolla una porción externa y otra interna, las llanuras mareales y el canal superior (Fig. 2). El subsistema de Santander desarrolla unas llanuras arenosas extensas, surcadas por dos canales mareales escasamente funcionales en la actualidad. Las unidades morfosedimentarias son mucho más variadas en el subsistema de Cubas, destacando la presencia de un delta mareal de flujo en la franja $\mathrm{N}$ de la bahía interna (Flor y Flor-Blanco, 2014a).

\section{Geología}

La morfología en planta de la bahía, mejor representada por el subsistema de Santander (Fig. 2), ocupa una franja de dirección NE-SO en cuyo subsuelo afloran rocas evaporíticas, limos, arcillas abigarradas de tonos rojizos, verdosos y grises y yesos del Keuper, flanquedas por sendas fallas NE-SO y fracturas (Sáiz de Omeñaca et al., 1981), pudiendo la inyección salina haber generado cabalgamientos locales. Se han descrito varios diapiros en el ámbito de este subsistema, como los de Santander, ría de Solía (continuación del de Parbayón), Penagos y Marina de Cudeyo y Solares (Ramírez del Pozo et al., 1974). Afloran materiales cretácicos en los bordes de la bahía, representados por facies arenosas y limosas wealdenses, calizas fosilíferas aptienses y alternancias de areniscas y limolitas del Albiense-Cenomaniense Inferior.

Los trabajos pioneros de Dantín Cereceda (1917) hacen referencia a una plataforma litoral elevada a $60 \mathrm{~m}$ de altura, que ha sido seccionada por ríos y estuarios. En realidad, el relieve marginal de la bahía lo constituyen diferentes niveles de rasa (Moñino et al., 1988; Flor y Flor-Blanco, 2014b), que se escalonan a diferentes alturas y, en la avenida del General Dávila en la culminación de la ciudad de Santander, se extiende este nivel con alturas de 70-80 m (equiparable al de $60 \mathrm{~m}$ ).

\section{Agentes dinámicos}

Los oleajes dominantes en el mar Cantábrico son del cuarto cuadrante con alturas de ola significantes inferiores a los 2,0 $\mathrm{m}$ y periodos comprendidos entre
8 y 12 segundos (Hellín Medina, 2011), siendo del $\mathrm{NE}$ cuando se suceden condiciones anticiclónicas, mientras que los de tormenta típicas son de 4,0 m (Losada et al., 1991). Los trenes de ola dominantes varían del ONO a NO, afectando a una mayor exposición de playa expuesta de la barrera confinante, mientras que los incidentes en la punta de la espiga de Somo-El Puntal provienen del NE, consecuencia de una refracción y difracción intensas, que son muy oblicuas a la costa (Falqués et al., 2006).

Con oleajes de tormenta del NO se produce una sobreelevación en el interior estuarino variable de 0,30 a $0,50 \mathrm{~m}$, con cifras algo menores en el caso de oleajes del NE (APS, 2012a). Dentro de la bahía, actúan los oleajes del SO, principalmente, y SE, que, durante las pleamares, removilizan las playas estuarinas de los sectores Pedreña-Elechas y toda la franja meridional de la flecha de Somo y las playas del sector occidental conocidas como Los Peligros-La Magdalena-Bikinis (Fig. 3b), formando parte estas de la propia ciudad de Santander.

Las mareas son semidiurnas y mesomareales, cuyas vivas máximas tienen cotas de 5,464 m y mínimas de $0,033 \mathrm{~m}$, con el nivel medio del mar (rango mareal) de 2,85 m (APS, 2012a), siendo los rangos medios máximos de 4,86 m y los mínimos de 1,49 m (calculados para las mareas de 2015). Se produce una cierta amplificación de la onda mareal desde mar abierta por lo que se comporta como hipersincrónico, similar al de San Vicente de la Barquera (Flor-Blanco et al., 2015b).

Existe un desfase horario por el cual la marea experimenta un retraso de unos 40 minutos hasta el interior del subsistema de Santander, registrado en la localidad de El Astillero, y de 2,6 horas entre la zona exterior de la Bahía y la parte más interna del subsistema de Cubas, reduciéndose la amplitud de la marea hacia la cola (APS, 2012b). La corriente de llenante en el subsistema de Santander penetra por el costado occidental y el canal central, mientras que el flujo de vaciante se ubica más al $\mathrm{E}$, con velocidades del orden de los $0,5 \mathrm{~m} / \mathrm{s}$, siendo máximos en ambos momentos mareales con una velocidad de $1 \mathrm{~m} / \mathrm{s}$ en la desembocadura, pero con sentidos opuestos. Las corrientes de vaciantes son superiores, pudiendo alcanzar los 3,0 nudos $(1,54 \mathrm{~m} / \mathrm{s})$ en mareas vivas, que 
a)

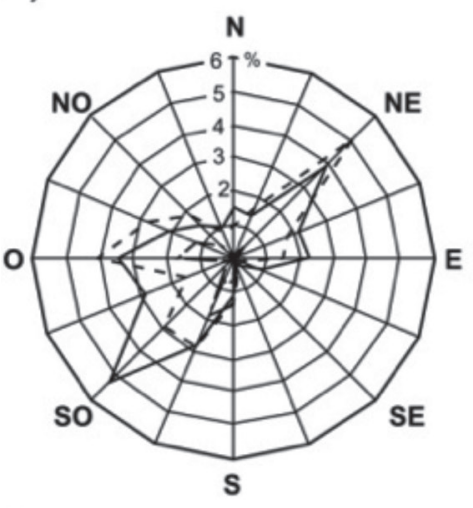

c)

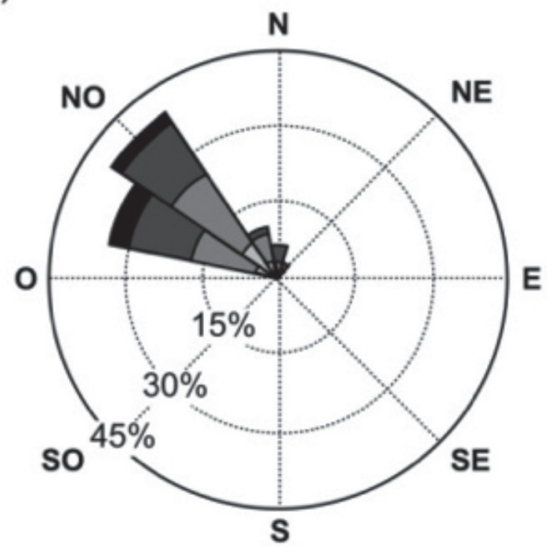

$\mathrm{Hs}<8 \quad \mathrm{Hs}<4 \quad \mathrm{Hs}<2 \quad \mathrm{Hs}<1$ b)
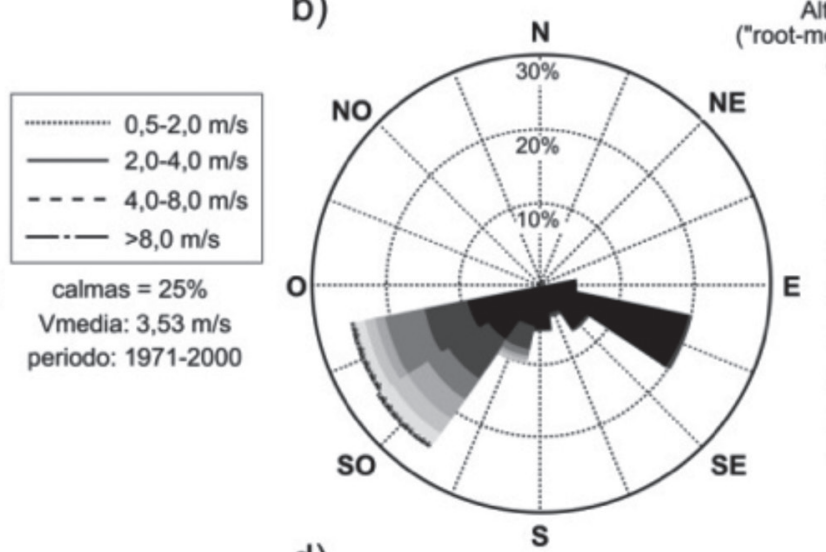

Alturas medias de ola

d)

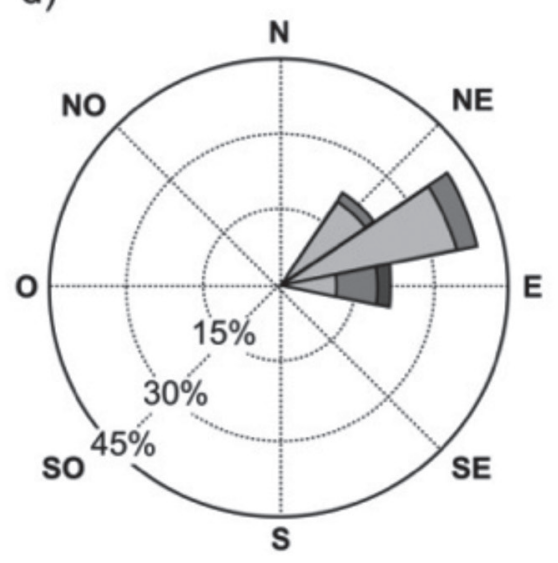

$\mathrm{Hs}<2 \mathrm{Hs}<1 \mathrm{Hs}<0,5$

Figura 3. a) Rosas de vientos; (b) oleajes (Pellón et al., 2014) en el interior del estuario, donde se producen componentes principales del tercer cuadrante; c) Incidencia de oleajes en aguas profundas, y d) y en el extremo de la espiga de El Puntal (derecha), de acuerdo con Medellín et al. (2009).

se incrementa aún más durante episodios de lluvias por mayor descarga del río Miera, en cuyo ámbito de influencia puede alcanzar velocidades de hasta 5 nudos $(2,60 \mathrm{~m} / \mathrm{s})$ (APs, 2012a). Las llenantes en el subsistema del Cubas culminan hacia la pleamar por el costado septentrional, cuyas corrientes siguen en sentido hacia el E como lo demuestran las formaciones de ondas de arena y su migración en dicho sentido (Pellón et al., 2014).
Las descargas del río Miera suponen un caudal medio anual de $8,23 \mathrm{~m}^{3} / \mathrm{s}$ en que la mayor parte de la cuenca hidrográfica intermedia y baja atraviesan rocas carbonatadas mesozoicas, lo que determina una reducción de la escorrentía por infiltración y el funcionamiento de la circulación subterránea (coeficiente bajo de 0,56 ) (Tabla 1). Los máximos y mínimos caudales son de $140,70 \mathrm{~m}^{3} / \mathrm{s}$ y de $0,50 \mathrm{~m}^{3} / \mathrm{s}$, respectivamente (DMAC, 2012).

\begin{tabular}{|c|c|c|c|c|c|c|c|}
\hline $\begin{array}{l}\text { superficie } \\
\left(\mathrm{km}^{2}\right)\end{array}$ & $\begin{array}{l}\text { longitud } \\
(\mathrm{km})\end{array}$ & $\begin{array}{c}\text { perímetro } \\
(\mathrm{km})\end{array}$ & $\begin{array}{c}\text { pendiente } \\
\text { (\%) }\end{array}$ & $\begin{array}{l}\text { precipitación } \\
\text { media anual } \\
(\mathrm{mm})\end{array}$ & $\begin{array}{l}\text { caudal } \\
\text { medio } \\
\left(\mathrm{m}^{3} / \mathrm{s}\right)\end{array}$ & $\begin{array}{l}\text { aportación } \\
\text { media anual } \\
(\mathrm{mm})\end{array}$ & $\begin{array}{c}\text { coeficiente } \\
\text { de escorrentía }\end{array}$ \\
\hline 296,38 & 45,6 & 116,3 & 33 & 1554,4 & 8,23 & 875,3 & 0,56 \\
\hline
\end{tabular}

Tabla 1. Datos geográficos e hidrológicos de la cuenca fluvial del río Miera (DMAC, 2012). 


\section{Metodología}

Se ha llevado a cabo un seguimiento histórico de la bahía de Santander gracias a la copiosa documentación existente, tanto de planos topográficos y batimétricos, como de fotografías verticales y las memorias de la gestión portuaria sobre dragados y ampliaciones de las instalaciones y otros documentos municipales y regionales.

Para determinar los cambios ambientales, se han cartografiado las unidades morfosedimentarias y dinámicas superficiales mayores, equiparables a facies sedimentarias. El seguimiento evolutivo se realiza a partir de hitos representativos desde una primera reconstrucción de la distribución original con mayor énfasis en los deltas de flujo y barra de desembocadura, así como en la barrera confinante El Puntal-Somo (espiga de Somo) y su campo dunar culminante. Se tienen en cuenta los volúmenes de dragado desde el desarrollo intensivo de la ampliación portuaria y la incidencia en el desarrollo de la espiga de Somo.

Se han consultado los numerosos planos y cartas de esta bahía desde el siglo XVII, algunos con batimetrías de cierto detalle, como los de Arévalo y del Campo (1843), el cual ha servido de punto de partida para la primera cartografía en un entorno prácticamente natural. Se revisaron otros próximos a este periodo, como los de Peńarredonda (1870), Orense (1875) y Lequerica (1878).

Las siguientes cartografías históricas de las unidades superficiales fueron elaboradas a partir de juegos de fotografías aéreas verticales: 1945 y 1956 de las Series $\mathrm{A}$ y $\mathrm{B}$, a escalas 1:44.000 y 1:33.000, respectivamente, del Army Map Services, usa (cedidos por el IGN); 1973, escala 1:18.000 (IGN); 1985, escala 1:30.000 (IGN); revisión con fotograma de 1988, escala 1:15.000; ortofotografía de 2014 a escala 1:5.000 (IGN-Diputación de Cantabria). También se han cotejado fotografías oblicuas y satelitales cuya procedencia son las plataformas web de Google Earth, Bing Maps, así como los últimos mapas topográficos detallados (1/5.000) del Servicio de Cartografía del Gobierno de Cantabria (http://www.territoriodecantabria.es/visor/).

\section{Resultados}

\section{Evolución histórica de la bahia}

Las transformaciones ocurridas en la bahía de Santander se achacan, fundamentalmente, al desarrollo portuario y la consiguiente expansión urbana de la ciudad, que han dispuesto de un espacio natural estuarino para ser intervenido de una manera más o menos continua. Para este trabajo se han tenido en cuenta los cálculos de las superficies estuarinas antropizadas, que incluye las originales (Tabla 2).

Este estuario es el de mayor superficie de la costa cantábrica, con una extensión actual de $23,46 \mathrm{~km}^{2}$ y un perímetro de $97 \mathrm{~km}$ (DMAC, 2012), si bien los autores no llegan a un acuerdo en ambas cifras. El perímetro natural afectado por el alcance del agua en mareas, oleajes internos y avenidas, bien sean bordes

\begin{tabular}{lcc}
\hline & $\begin{array}{c}\text { Cendrero y Díaz de Terán (1977) } \\
\mathrm{km}^{2}\end{array}$ & $\begin{array}{c}\text { Rivas Mantecón (2000) } \\
\mathrm{km}^{2}\end{array}$ \\
\hline Superficie total original & 43,345 & 45,14 \\
Superficie total en 1975 & 24,452 & --- \\
Superficie intermareal original & 34,765 & --- \\
Superficie intermareal en 1975 & 14,872 & --- \\
Superficie intermareal en 2000 & $-\ldots--$ & 22,50 \\
\hline
\end{tabular}

Tabla 2. Superficies naturales y funcionales del conjunto estuarino de Santander en diferentes años, según los autores que han calculado su extensión. 
fangosos y de marisma, playas estuarinas, márgenes de canales mareales y acantilados se ha calculado en $38,56 \mathrm{~km}$, mientras que los bordes rígidos, constituidos por muelles, diques de aislamiento, paseos, etc. suman un total de $35,56 \mathrm{~km}$, añadidos a los anteriores. Sedimentariamente, está muy colmatado en su conjunto, aunque las amplias llanuras arenosas del subsistema de Santander solamente emergen unos centímetros durante bajamares muy vivas.

El prisma mareal medio de la bahía de Santander es de $68,19 \mathrm{hm}^{3}$ (Jiménez et al., 2012) o bien de 74,5 $\mathrm{hm}^{3}$ (APS, 2012b), que contrasta con el original en mareas vivas, estimado en $180 \mathrm{hm}^{3}$ en el siglo XVIII o como detallan Losada et al. (1991) de $87 \times 10^{6} \mathrm{~m}^{3}$ y una descarga máxima de $5500 \mathrm{~m}^{3} / \mathrm{s}$. Para el subsistema del Cubas se estima en $3,70 \mathrm{hm}^{3}$, con 5,80 $\mathrm{hm}^{3}$ en mareas vivas y $2,00 \mathrm{hm}^{3}$ en muertas (APS, 2012b).

Una primera instantánea en tiempos medievales, desde el siglo XII (Pozueta Echavarri, 1985), certifica el estado original con la excepción de la superficie urbana de Santander que aprovechaba las márgenes, constituidas por playas arenosas estuarinas y una estrecha franja de llanuras fangosas y marismas, así como un canal mareal, que separaría posteriormente las pueblas vieja y nueva. La mayor parte del espacio urbano subplano de la ciudad corresponde a antiguos bordes de llanuras de fangos que fueron rellenadas para construir muelles, avanzando la línea de tierra hacia el canal principal.

A partir de los proyectos de ampliación de la ciudad y su puerto, verdadero factor impulsor (Martín Latorre, 2010), como el Ensanche hacia el OSO de Llovet en 1765 y numerosos posteriores en el siglo XIX, de mayor envergadura, se llegó a la elaboración del Plan de Estabilización, iniciado en 1959. Se trataba de densificar la trama industrial cuyo apogeo se manifestaba en el desarrollo comercial portuario.

El registro de 1956 representa los comienzos de este periodo de apogeo y crisis del modelo industrial, desde 1959 a 1985 (Martín Latorre, 2010). Se intensificó la industrialización con ganancia de población, resintiéndose con la crisis del petróleo a mediados de los 70. Las instalaciones portuarias se desviaron a la margen SO, en las marismas de Raos
(Fig. 2), que necesitaron de rellenos, construcción de muelles, instalaciones y equipamientos. Se continuó la ocupación de marismas hacia el $\mathrm{O}$ y el $\mathrm{S}$, fundamentalmente sobre las marismas de Raos, donde se emplaza el aeropuerto de Santander.

La instantánea de 1985 atiende mejor al precedente de la distribución actual, que se ha denominado como etapa de la terciarización, sociedad de la información y globalización (Martín Latorre, 2010).

\section{Etapa original}

El mapa más antiguo disponible por su mayor calidad cartográfica, representativo de las condiciones de mayor naturalidad de la mayor parte de la bahía, corresponde al elaborado por Arévalo y del Campo en 1843 (Fig. 4A). El levantamiento batimétrico detallado permite reconstruir numerosas formas de lecho arenosas de grandes dimensione, así como la incisión de los canales y rampas de alto flujo.

Aunque no figuren algunas unidades morfosedimentarias y dinámicas características, es fácil considerar que las mayores superficies estaban ocupadas por marismas, como se infieren de los datos históricos (Pozueta Echevarri, 1985; Ferrer Torío y Ruiz Bedia, 1991; González Urruela, 2001; Martín Latorre, 2010), así como de los numerosos espacios que se conservan relativamente naturales en la actualidad. Es particularmente interesante y fiable este plano en la distribución de las grandes formas arenosas de lecho que permite reconstruirlas cartográficamente con una gran fiabilidad: barra de desembocadura y delta mareal de flujo con sus rampas correspondientes, que fueron eliminadas paulatinamente para mejorar la navegación, así como del canal principal (Fig. 4B).

Se ha seleccionado la amplia franja de la bocana desde el entorno de Las Quebrantas hasta el extremo $\mathrm{NO}$ del gran bancal arenoso ( $\mathrm{N}$ de los páramos de la Huera Grande). Las grandes formas de lecho del interior del subsistema de Santander se continúan adosadas al canal principal, aguas arriba (Fig. 5).

Básicamente, el paso de desembocadura sobre el que se conduce la masa de agua en llenantes y vaciantes en el extremo del ciclo mareal, construía, tanto ha- 
A)

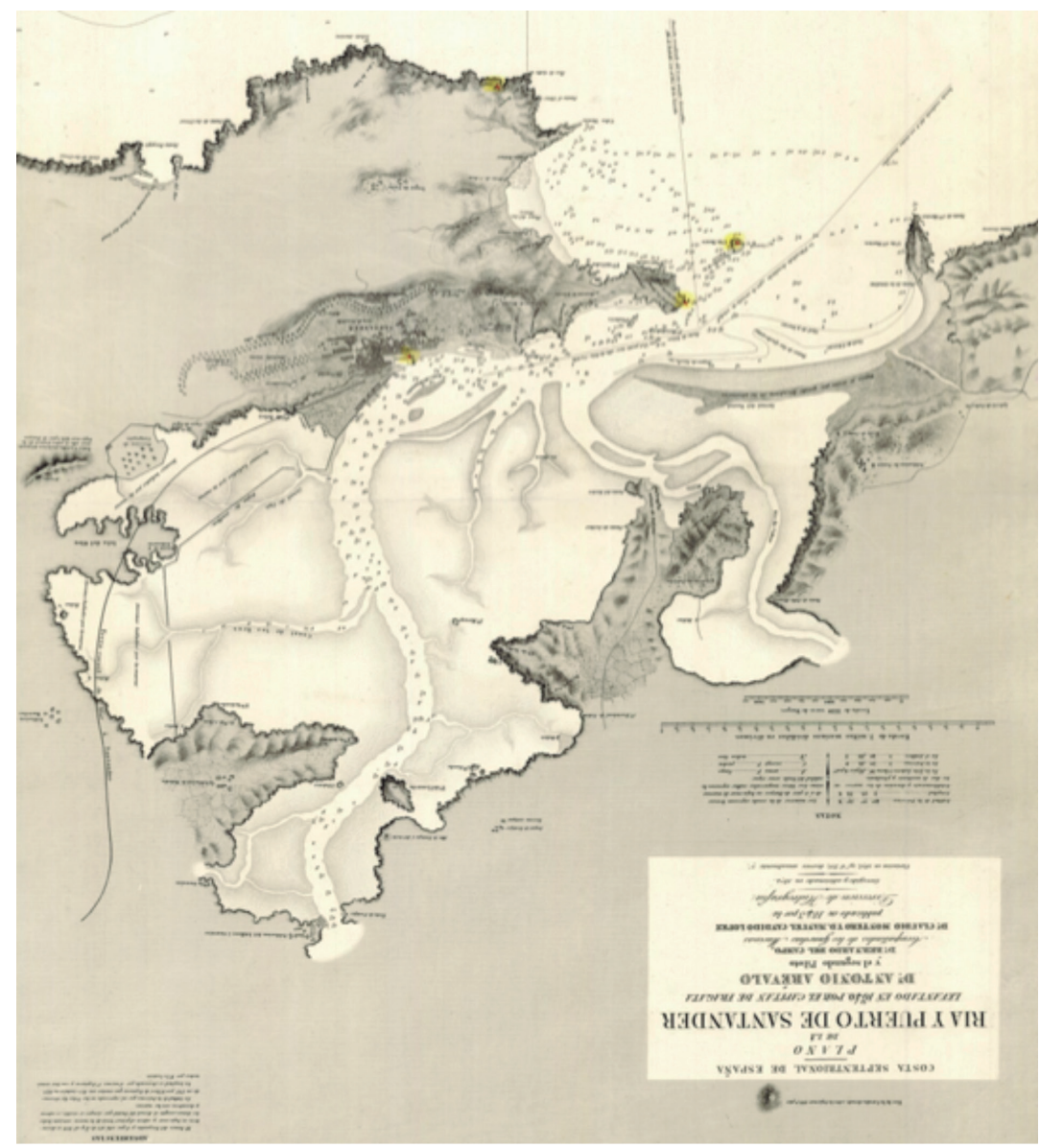

B)

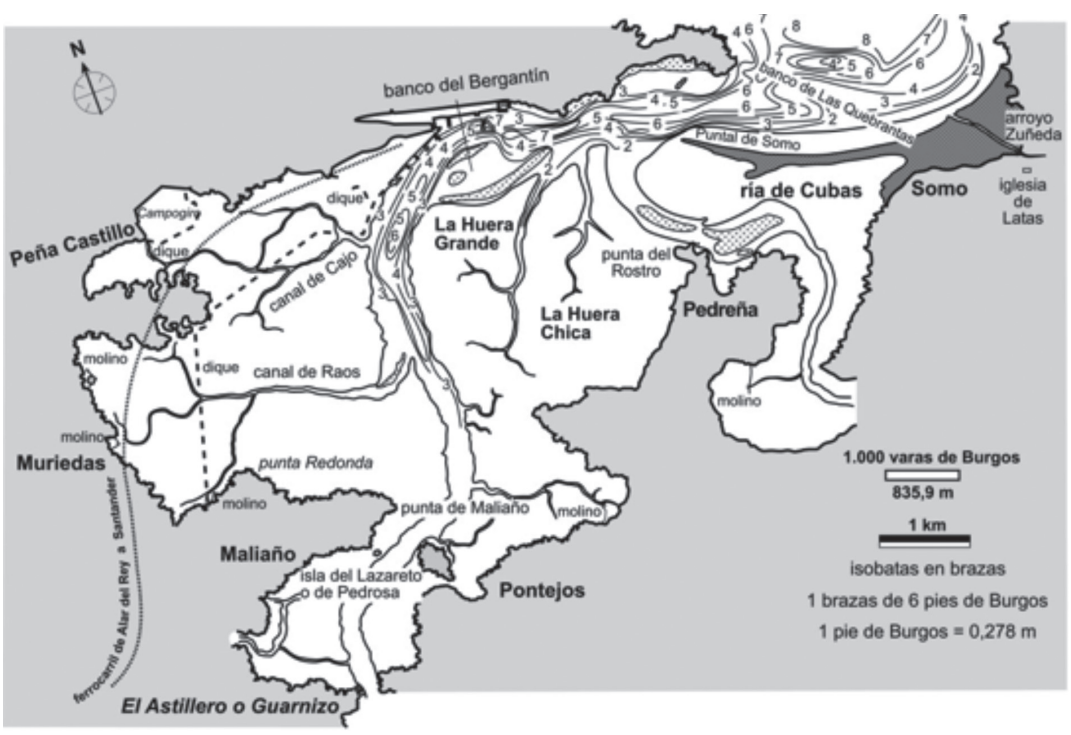

Figura 4. A) Plano original de Arévalo y del Campo (1843) de la versión http://bibliotecavirtualdefensa.es/BVMDefensa/i18n/ consulta/registro.cmd?id=706Plano r5. B) Reconstrucción morfológica del plano original de Arévalo y del Campo (1843), corregido y aumentado en 1874, que muestra el conjunto estuarino todavía en estado relativamente natural y las batimetrías expresadas en contornos del canal principal y todo el frente sumergido externo. La traza definitiva del ferrocarril se acabaría ubicando algo más al E en la franja meridional. 

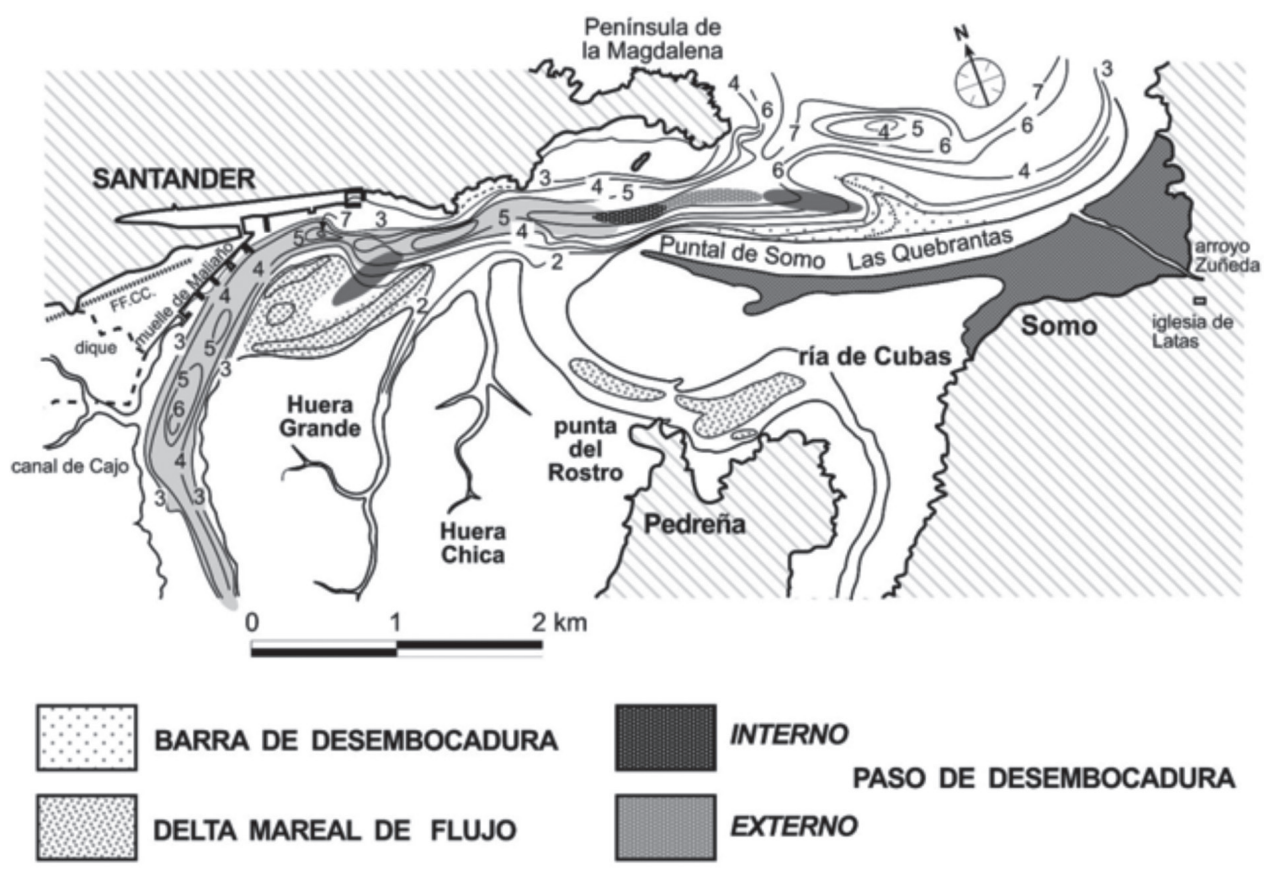

CANAL PRINCIPAL

RAMPA DE ALTO FLUJO
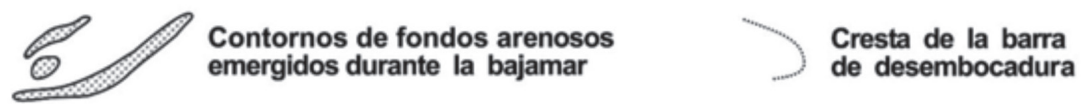

Figura 5. Reconstrucción de las batimetrías (brazas de Burgos) y grandes formas de lecho más importantes, incluidos el canal principal, paso de desembocadura interno y externo y rampas de alto flujo de la barra de desembocadura y delta mareal de flujo, a partir del plano detallado de Arévalo y del Campo (1843) (modificado de Flor y Flor-Blanco, 2014a).

cia el interior del estuario como mar afuera, sendas estructuras arenosas de alto flujo capaces de disipar la energía desarrollada en el proceso. No obstante, se detecta una depresión sumergida estrecha, de gran calado y arqueada entre el extremo E de la península de la Magdalena y el ápice distal del brazo bien desarrollado de Las Quebrantas (Figs. 2 y 5), posiblemente con un funcionamiento mareal. El paso estaba representado por un canal largo de algo más de $1 \mathrm{~km}$ y unos $150 \mathrm{~m}$ de anchura, con una dirección O-E, y cuya gran extensión se debía a la prolongación al exterior a través de un tramo no confinado (paso exento), como se reproduce actualmente en el estuario de Navia (López Peláez, 2015), y más reducido en los de Niembro (Asturias) y Tina Mayor (Flor-Blanco, 2007). También hacia el interior se prolongaba para enlazar con la rampa del delta mareal de flujo, situado al S de la ciudad de Santander. Las máximas profundidades alcanzaban cifras de aproximadamente $10 \mathrm{~m}$ (Fig. 5).
Desarrollaba una amplia barra de desembocadura, denominada de Las Quebrantas, que ha sido interpretada como un bancal de playa (Losada et al., 1991), pero en este caso se considera que está más en consonancia con una amplia terraza de bajamar de la playa expuesta perteneciente a la extensa espiga de Somo-El Puntal (Figs. 4 y 5). A juzgar por la reiteración de los diferentes planos, debía dibujar una planta en $\mathrm{V}$ incompleta con los brazos asimétricos algo curvados cuya convexidad apuntaba hacia el costado oriental de la gran playa expuesta de Somo-Loredo. $\mathrm{Su}$ brazo derecho (S) estaba indisolublemente vinculado a la terraza de bajamar, quedando la rampa alineada O-E y el brazo izquierdo (NE) orientado al $\mathrm{NO}$ y una disposición exenta. Esta estructura tenía el eje orientado hacia el ESE más o menos paralelo a la disposición de la espiga de Somo-El Puntal (Fig. 5). También los oleajes incidentes del NO se modificaron por la península de La Magdalena hacia el $S$, produciéndose una refracción y difracción (Lo- 
sada et al. 1991) sobre esta estructura, favoreciendo su desarrollo. Permaneció siendo funcional al menos hasta 1922, y, probablemente hasta mediados del XX, según los planos históricos de la Autoridad Portuaria de Santander (Planos Generales de la Bahía: http://www.puertosantander.es/cas/cartografia_historica.aspx). Esta área se constituye en el punto de inflexión de la espiga de Somo-El Puntal en dos mitades, desde el cual los transportes arenosos por derivas longitudinales de la playa se mueven hacia el E y O (Losada et al., 1991).

El paso de desembocadura enlazaba hacia el interior de la bahía con un amplio delta mareal de flujo, cuyos rebordes emergían durante las bajamares vivas, como figura en la leyenda del plano de Arévalo y del Campo (1843), entre los que destacaba el banco arenoso del Bergantín. Estaba constituido por una rampa estrecha de alto flujo y un extenso bancal arenoso algo asimétrico, cuya longitud máxima se registraba en el costado meridional con $1350 \mathrm{~m}$ y $900 \mathrm{~m}$ en el septentrional. La anchura era de $750 \mathrm{~m}$, conformando una planta acorazonada con la convexidad apuntando hacia el interior del estuario. En el subsistema del Cubas, aunque no se detalla una estructura de las mismas características, se comprueba su existencia desde al menos la fotografía aérea de 1945 (Fig. 6).

El canal principal se ubicaba en el borde septentrional, debido al efecto de Coriolis, con las mayores profundidades en posición casi central, algo superiores en el lugar donde se sitúa el canal mareal de Cajo. Se unía al paso de desembocadura interno a la altura de la punta Rabiosa de aquel momento, que se continuaba por un paso externo o exento y este enlazaba, también insensiblemente, con la rampa de la barra de desembocadura de Las Quebrantas, donde el calado era paulatinamente menor, formando un arqueamiento laxo con la convexidad hacia el N (Fig. 5).

A finales de siglo xIx y primeros del xx (comienzo de la I Guerra Mundial) se alcanzó el máximo esplendor en la explotación de minerales de hierro en el área meridional de la bahía (alrededores de la sierra costera de Peña Cabarga), que languideció en los 80 del siglo xx. Se construyeron lavaderos y balsas principalmente en la confluencia de los brazos de Solía y Tijero (Cueto Alonso, 2006). Quedaron colmatadas estas rías, así como la de Boo y todo el conjunto del
Astillero, que se extiende desde la confluencia de las primeras hasta esta última más septentrional (Fig. 2). Habitualmente los espacios laterales de estos canales mareales culminaban con vegetación marismeña, predominantemente de agua dulce, mientras que algunas llanuras solo eran fangosas y sus llamativos limos rojizos procedían de los vertidos del lavado.

\section{Evolución desde 1945 hasta 1973}

Entre los primeros documentos gráficos, se dispone de la fotografía aérea vertical de la Serie A del vuelo de 1945 (Fig. 6). Aunque su calidad no es la deseada, ofrece una visión directa de los rellenos en curso de las marismas de Raos (SO de la ciudad de Santander) y se constata la desaparición del gran delta mareal de flujo del subsistema de Santander y de la barra de desembocadura. El canal principal y su continuación por las rampas de los antiguos delta mareal y paso desembocadura interno y externo ha sido perfilado como «la canal» de navegación. Se desprenden otras consideraciones de mayor escala, como la distribución de las amplias llanuras arenosas y sus canales mareales y de la espiga de Somo-El Puntal, apuntando su segmento externo con una dirección NO-SE. La margen oriental del subsistema de Santander y la totalidad del de Cubas, excepto las marismas del Conde y del meandro de Suesa (Fig. 2 ), conservaban un estado relativamente natural.

La mejor evidencia gráfica, tanto por su gran calidad como haber sido realizada durante una bajamar viva, está representada por los juegos de fotografías aéreas de 1956 (Fig. 7). Se complementa con la Hoja N.o 1, Plano General de la Bahía, a escala 1/10.000 con curvas batimétrica y curvas de nivel de 1950, procedentes del Archivo Histórico del Puerto de Santander, antigua Junta de Obras del Puerto. A lo largo de estos 10 años que median entre ambos fotogramas, se continuaron los rellenos de las marismas de Raos y buena parte de las de Alday, fundamentalmente para ubicar el aeropuerto de Santander (Parayas), en cuyo extremo $\mathrm{SO}$ se practicó un canal artificial, de modo que los dragados dejaron contornos subcirculares en planta fácilmente identificables en la figura 6 .

El canal principal del subsistema de Cubas en la $b a-$ hía externa, con una dirección NO-SE, desarrollaba 


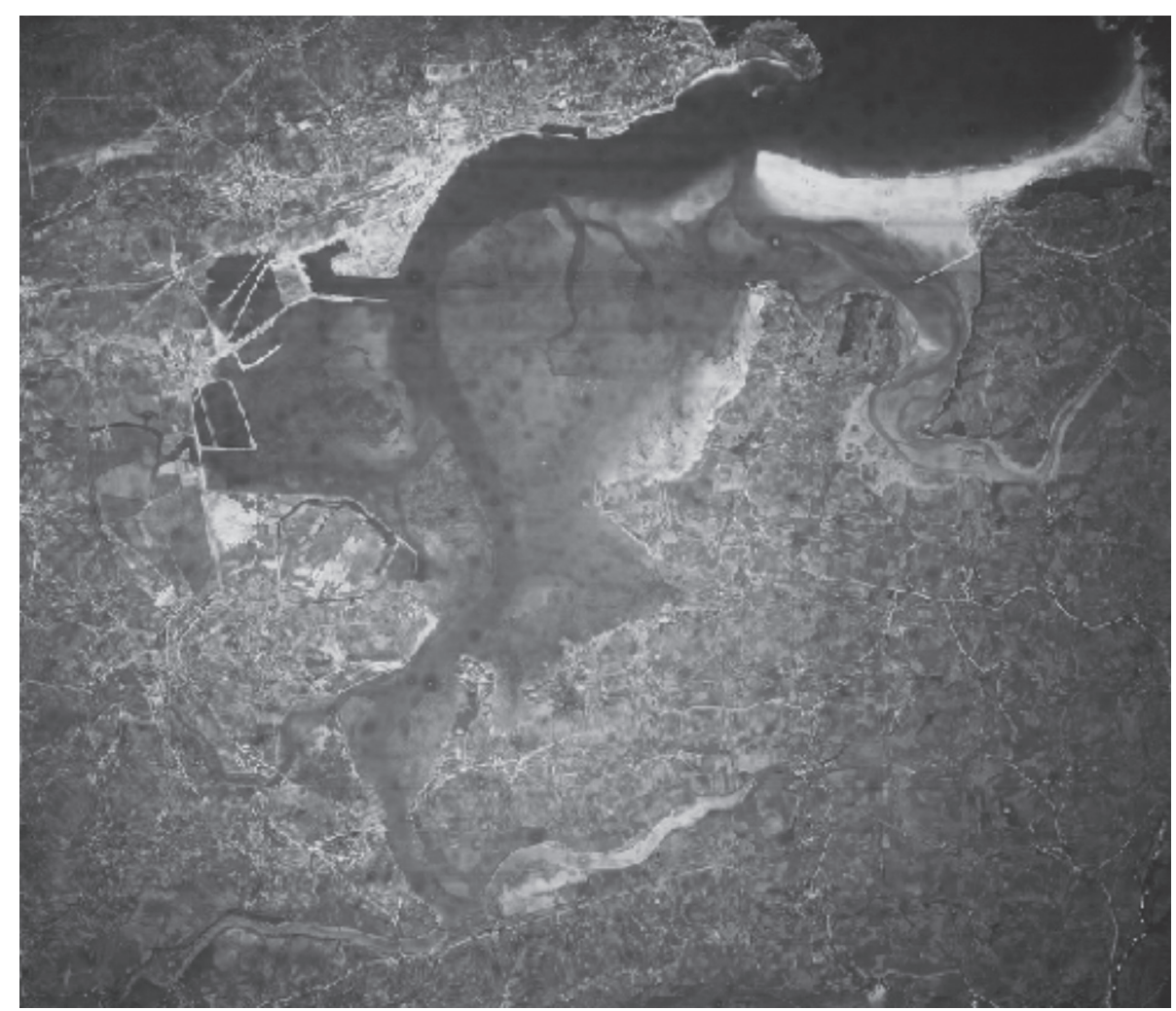

Figura 6. Fotografía aérea vertical de la bahía de Santander en 1945-46 (Army Map Service, usa) de la Serie A (escala original aproximada 1:44.000), obtenida en el IGN (http://fototeca.cnig.es/).

hacia la bahía interna un delta mareal de flujo, cuya posición se ha conservado hasta el presente (Fig. 2), aunque variando ligeramente su geometría en planta. El trazado de dicho canal se continuaba hacia la punta Rabiosa oblicuamente a la playa estuarina de la espiga de Somo, resolviéndose en una barra horquillada («spill-over lobe») estrecha y alargada con la misma dirección apuntada (Fig. 7), propia de condiciones de reflujo. Esta instantánea contrasta con la posición y trazado más sinuoso del canal principal, deducidos de los planos del siglo xIx (Fig. 5), que se adosaba a los márgenes de la localidad de Pedreńa.

Justo al NE de Pedreña, un gran bancal arenoso, colonizado por Zostera, ocupaba el área meridional del canal y la traza antigua sinuosa del canal en el segmento de Somo-Pedreña, este desarrollando numerosas barras arenosas menores, alguna de tipo horquillado y de meandro. Se extendió un dique sobre las marismas situadas al E de Pedreńa con el objetivo de ser rellenadas en años posteriores, lugar donde se ubica parcialmente el actual puerto deportivo y la carretera comarcal hasta conectar con el puente de Somo, todavía no construido.

En el vuelo de 1956, la espiga de Somo-El Puntal estaba desprovista de vegetación en su superficie culminante, pudiendo tratarse de dunas embrionarias o bien de un manto eólico tabular (Fig. 8A). En las fotografías aéreas verticales de 1973, se certifica por primera vez la presencia de dunas vegetadas muy escasas culminantes sobre la espiga de Somo-El Puntal, formando parches alargados. Eran, frecuentemente, fusiformes en planta y perpendiculares a la alineación de la espiga, con pasillos interdunares muy amplios, que fueron retocados por tormentas de ola. No obstante, muy anteriormente Dantín Cereceda (1917) describe que las más próximas a Somo estaban colonizadas pobremente y las especies eran escasas, entre las que dominaban Euphorbia paralias, Eryngium maritimum y Pancratium maritimum. Se evidencian los pasillos de erosión de ola, generadores de mantos de tormenta planares, que transferían arenas a la bahía externa del subsistema de Cubas; la mayor actividad se deduce te- 


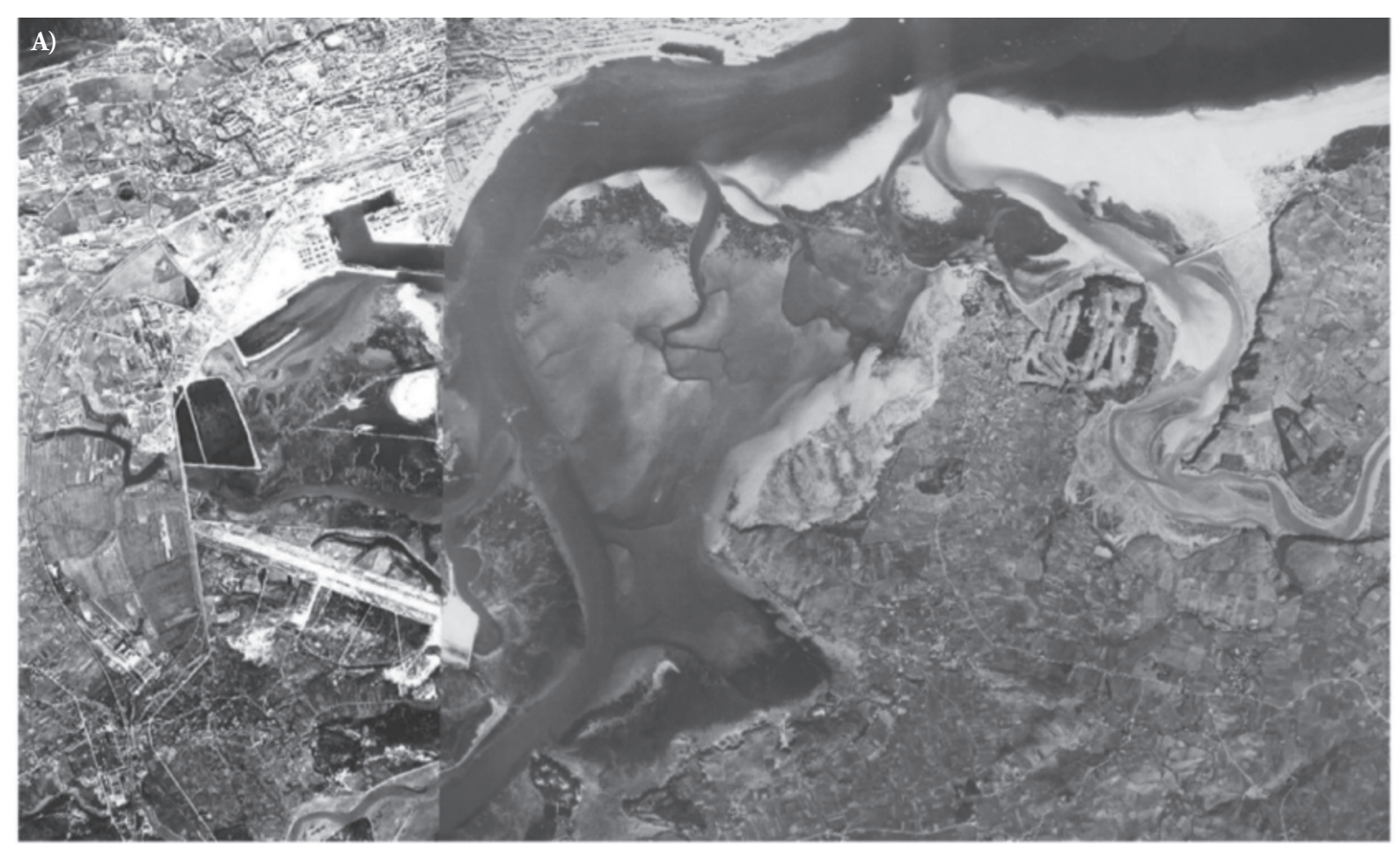

B)

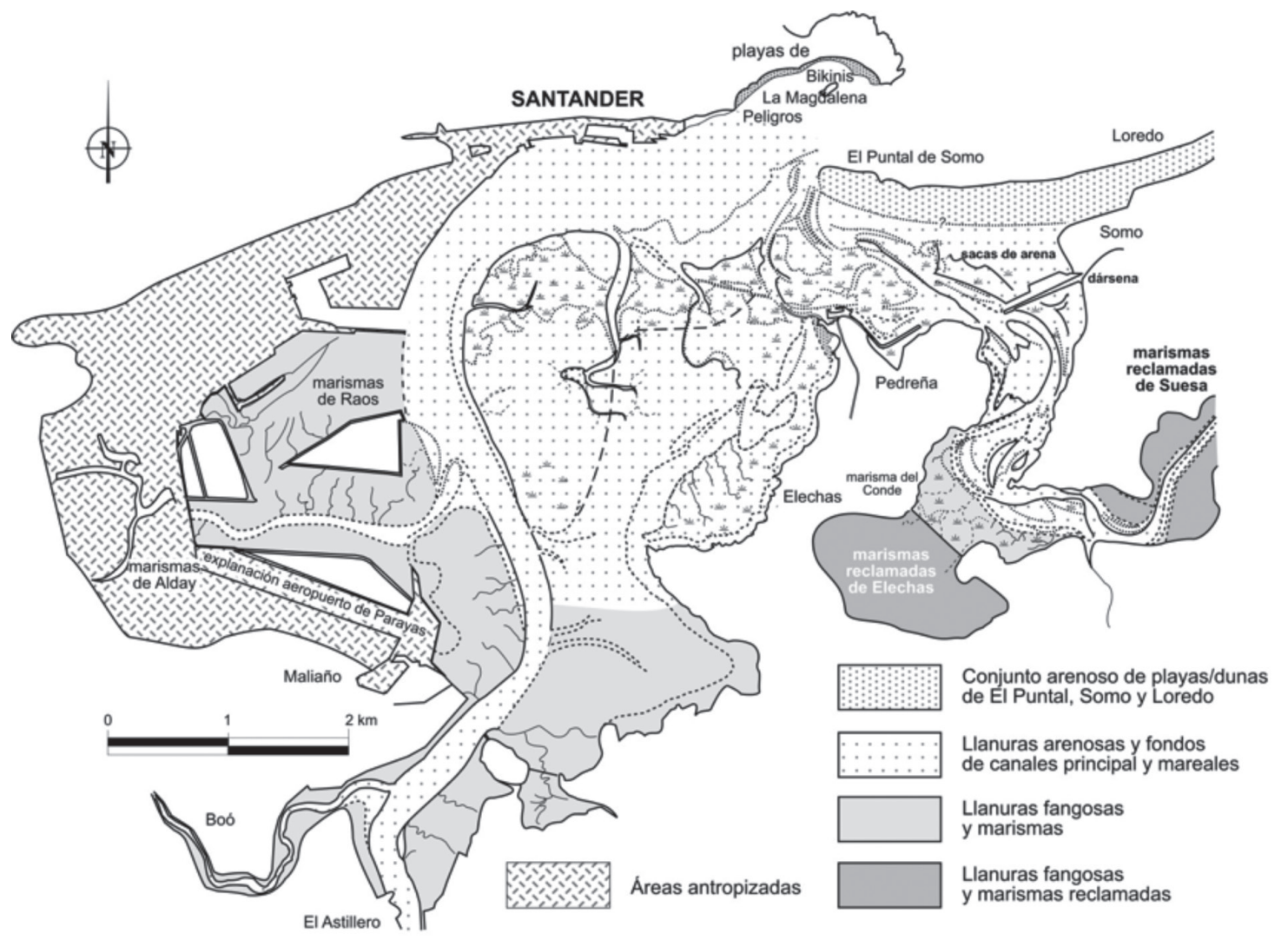

Figura 7. A) Composición fotográfica vertical de los vuelos 28980 y 28981 de octubre de 1956 del Army Map Service (escala original aproximada 1:33.000), obtenida en el IGN (http://fototeca.cnig.es/). (B) Cartografía simplificada de los fondos sedimentarios de la bahía de Santander elaborada sobre el fotograma anterior donde se constata el grado de ocupación de las marismas meridionales de la ciudad de Santander y la preparación de terrenos para el aeropuerto. 

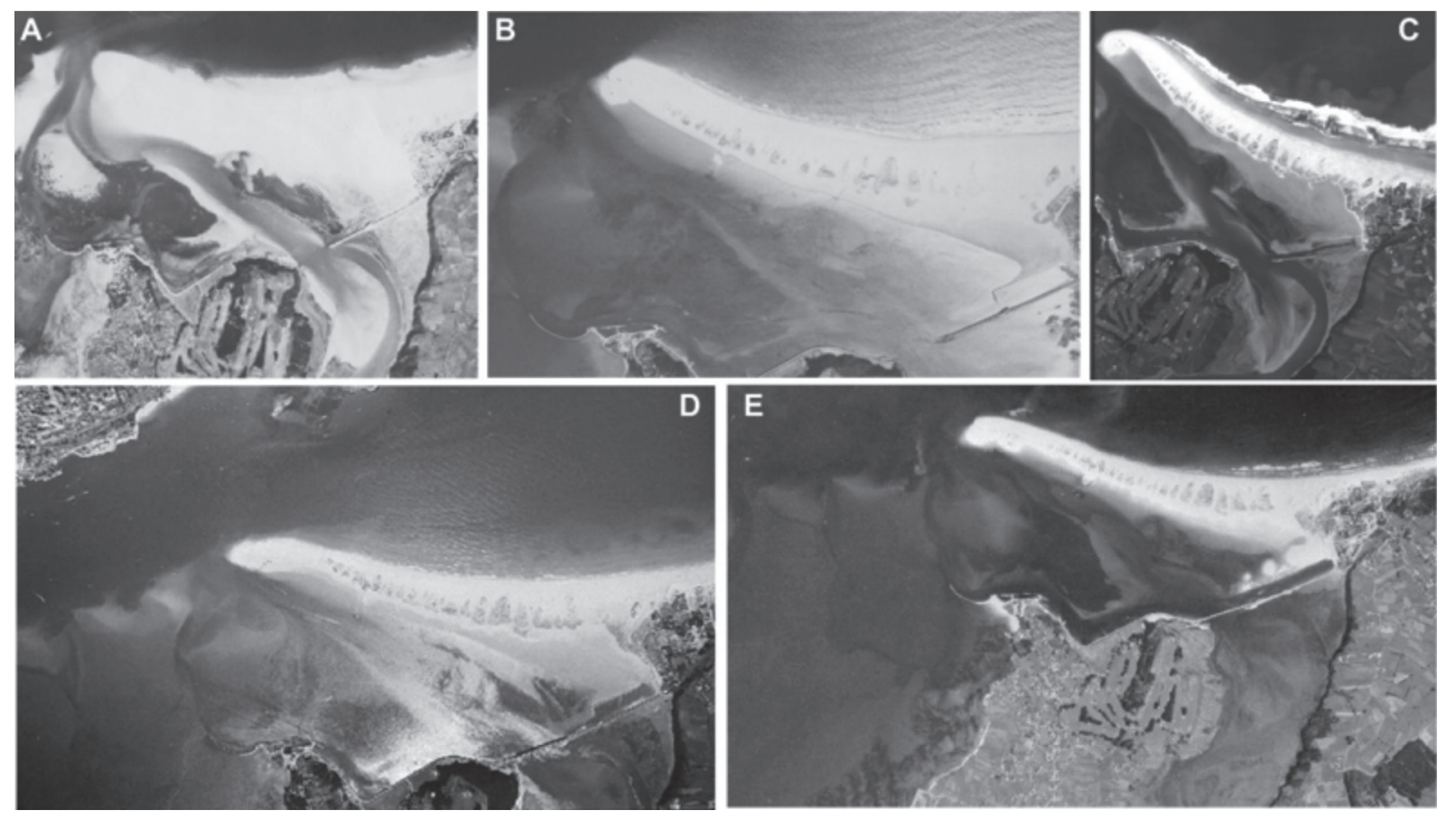

Figura 8. Instantáneas parciales de las fotografías verticales de la espiga de Somo-El Puntal y bahía del subsistema de Cubas de los ańos 1956 del Army Map Service, usA (A), 1970 de CETFA (B), 1974 de Aeropost para la Jefatura de Costas (C) y anteriores a 1978, vuelo interministerial 1973-1986 (D) y E) vuelo nacional de 1980-1986, obtenidas en el IGN (http://fototeca.cnig.es/).

nía lugar en el tercio oriental donde los afloramientos dunares vegetados eran más reducidos y se generaba una llanura arenosa amplia desde la dársena de Somo hacia el N y NO (Fig. 8B).

En 1974, se constatan las primeras colonizaciones vegetales de la duna culminante de la espiga de Somo (Fig. 8B), así como la formación de los pasillos de tormenta. La banda ocupada por las especies vegetales dunares se incrementa, lo mismo que el desarrollo de los pasillos en las instantáneas posteriores (Fig. 8C a E). Los rellenos sobre las marismas orientales de Pedreña habían tenido lugar entre el registro de 1956 y antes de los años setenta, espacio aprovechado en parte para ubicar la carretera comarcal CA-1141 que sirve de enlace al puente de Somo.

En el vuelo de 1973 (Fig. 8C), se repiten los mismos motivos de la etapa anterior. En la bahía externa, existía un amplio bancal arenoso, colonizado por vegetación, que servía de bifurcación para el canal principal. Éste circulaba por el costado septentrional en total continuidad desde la rampa de alto flujo del delta mareal (bahía interna) y el canal que discurre desde la dársena de Somo hasta Pedreña.

\section{Evolución desde 1973 hasta 1985}

En el juego de fotos Interministerial de 1973-1986, las dunas han crecido sobre la playa expuesta y los numerosos pasillos alcanzaban anchuras de unos pocos metros. Además, la punta Rabiosa había construido un bucle que servía para iniciar a posteriori el crecimiento de la espiga con el tramo convexo hacia la península de la Magdalena por el efecto de sombra de esta protuberancia a los oleajes en mar abierta del NO que se refractan hacia el SO (Fig. 8D). En cambio, en el interior de la bahía y las marismas, las modificaciones no fueron tan importantes (Fig. 9).

También se advierte en las fotografías más modernas desde 1980 a 1986 que el puente de Somo (CA-141), restringió parcialmente la dinámica y sedimentación entre las Bahías externa e interna del subsistema de Cubas, traduciéndose en una variación de la planta del delta de flujo mareal, deducible desde la Fig. 8A a la $8 \mathrm{C}$ y $8 \mathrm{E}$. El canal principal de este subsistema convivía con el nuevo canal funcional que comunica en la actualidad de forma permanente las dársenas de Somo y Pedreña, visible mejor en la Fig. 8E. Por otro lado, la espiga de Somo-El Puntal se prolon- 


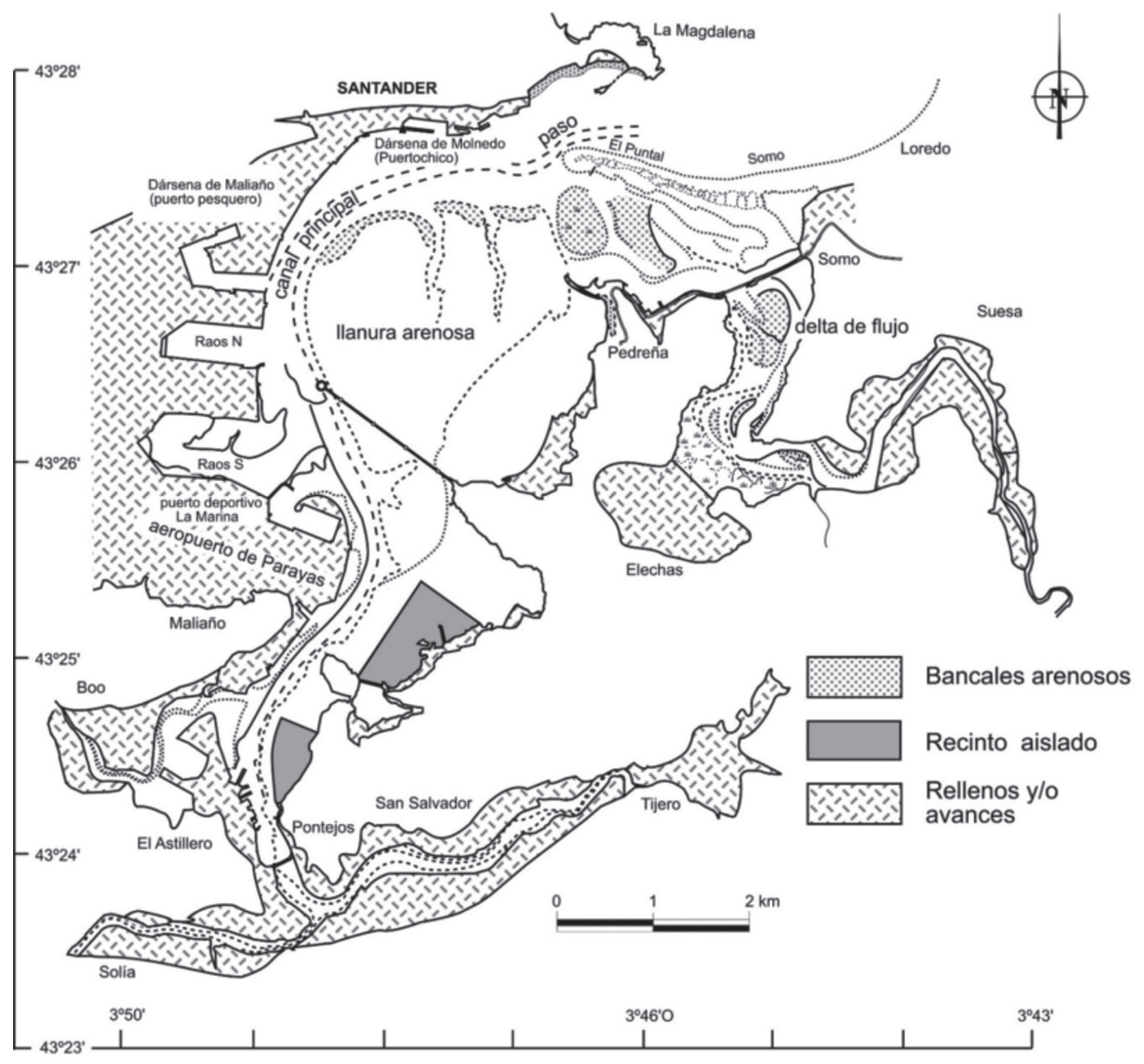

Figura 9. Cartografía simplificada de la bahía de Santander representativa de mediados de los años 80 con mayor énfasis en la distribución de las áreas desnaturalizadas.

gó hacia el O con una dirección O-E (Figs. 8A-E), habiendo comenzado un tiempo atrás el proceso de arqueamiento mencionado, que se consolida en esta década. En 1988, la cobertura vegetal del campo dunar culminante estaba relativamente bien desarrollada y la espiga se interrumpe por numerosos pasillos de tormenta. La anchura de la franja de playa inter y supramareal expuesta y estuarina, junto con el campo dunar, alcanzaba los valores máximos.

\section{Distribución actual (2015)}

Se conservan en buen estado las amplias llanuras arenosas $\left(5,65 \times 10^{6} \mathrm{~m}^{2}\right)$ colonizadas por vegetación diferencial de Zostera noltti y escasamente $Z$. marina y especies algales en la franja próxima a tierra, como son Gracilaria sp., Enteromorpha spp. y Ulva spp. (Puente Trueba et al., 2004); en la margen oriental del canal principal se desarrollan bancales arenosos, independizados por los canales mareales muy estables de las Hueras en posición septentrional (Fig. 10) que, de manera efímera, construyen deltas arenosos de reflujo sobre la margen oriental del canal principal. Estas llanuras apenas si quedan al descubierto en bajamares, excepto cuando se trata de mareas vivas.

El canal principal de la Bahía muestra una traza arqueada de casi $12 \mathrm{~km}$ de longitud abrazando la llanura arenosa, con dos ramales. El primero, de orientación E-O, tiene una anchura de 300-800 m y una profundidad entre 6 y 15 m; en el segundo, con una direc- 


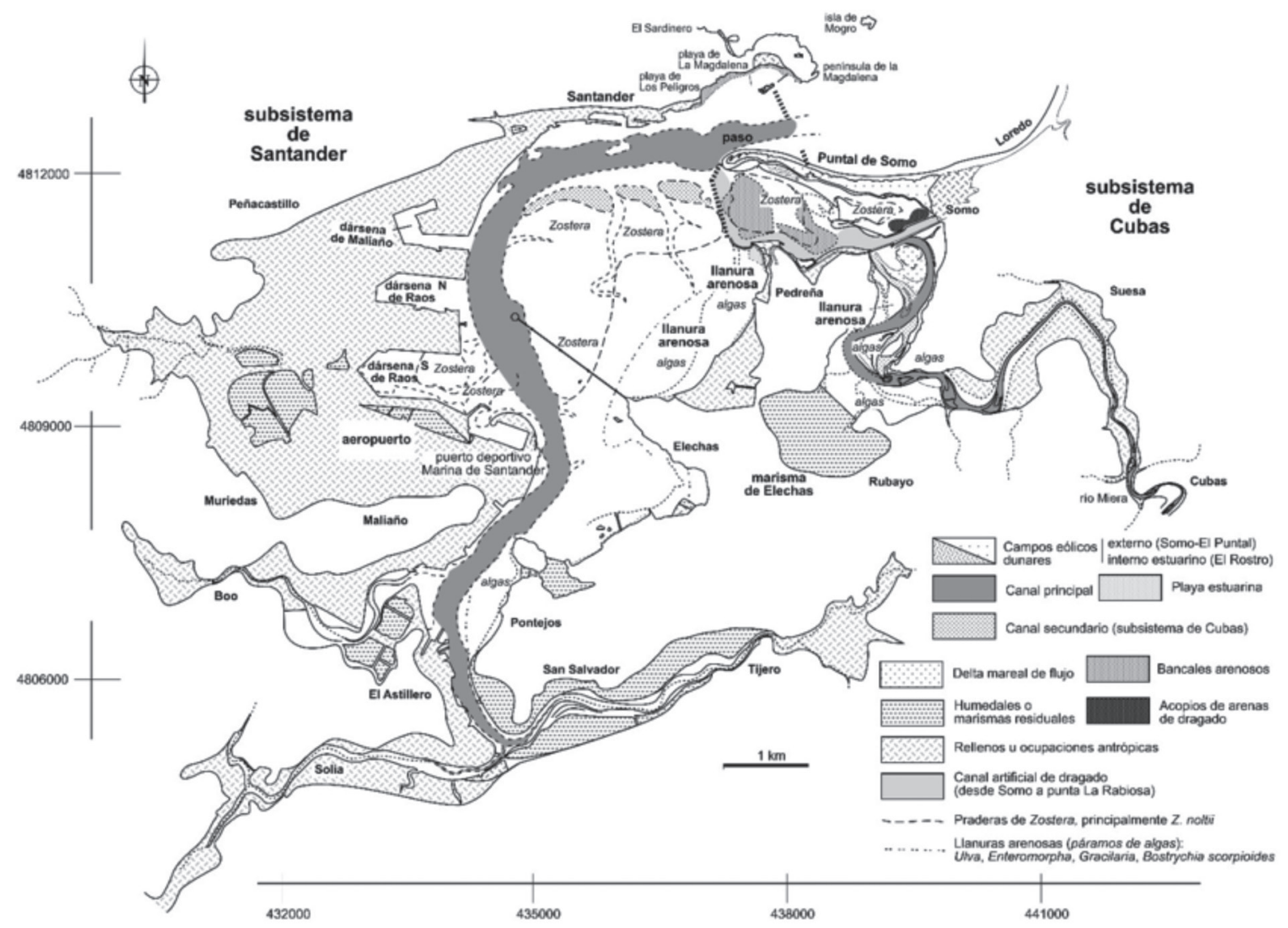

Figura 10. Cartografía actualizada de las unidades morfosedimentarias principales de la bahía de Santander representativa de 2015.

ción N-S, las anchuras están por debajo de los $500 \mathrm{~m}$ (en ocasiones se estrecha hasta los $150 \mathrm{~m}$ ) y calados entre 6 y 15 m (APS, 2012a). En el estuario interno, el canal principal descubre en bajamar sus márgenes con ondas de arena y algunas barras fango-arenosas, que pasan lateralmente de forma insensible a llanuras fangosas con una red densa de drenaje de canales mareales. Algunas matas de plantas halofíticas se instalan como marismas activas en varios brazos estuarinos.

Los rellenos de las antiguas marismas del costado occidental, principalmente, y avances hacia el canal principal y de las llanuras fluviomareales de los ríos costeros meridionales del subsistema de Santander han dejado unos vestigios testimoniales en los alrededores del aeropuerto y en el brazo estuarino de Boo; en la margen oriental, se ocuparon algunas superficies menores de marismas.

El subsistema de Cubas ocupa el valle fluvial excavado con anchuras reducidas, que se estrechan más o menos paulatinamente hacia la zona del canal superior. Desarrolla una zonación singular por cuanto no se individualiza un complejo de desembocadura y la bahía se segmenta en una parte externa $\left(1,87 \times 10^{6}\right.$ $\left.\mathrm{m}^{2}\right)$ y otra interna $\left(1,10 \times 10^{6} \mathrm{~m}^{2}\right)$. La bahía externa enlaza con la esquina NE de la bahía del subsistema de Santander, sobre la que se activan bancales arenosos cada vez más colonizados por Zostera noltii, y la interna sobre la que se encuentra funcional el delta mareal de flujo, en parte algo modificado desde la construcción del puente de Somo-Pedreña, y se extiende el canal principal con una traza muy sinuosa y numerosas barras laterales y de meandro y algunas horquilladas, también densamente colonizadas por vegetación (Fig. 10).

La amplia superficie interna abrigada por la espiga de Somo (bahía externa) está constituida por bancales arenosos muy colonizados por Zostera noltii y diferentes especies algales. Por el contrario, gran parte de sus marismas internas, pertenecientes a la zona de 
llanuras mareales, han sido desnaturalizadas, aunque dedicadas a labores ganaderas para lo que, únicamente, han requerido el aislamiento de los recintos mareales mediante diques; quedan franjas laterales al canal principal de marismas estrechas (máximo de $50 \mathrm{~m}$ ). Aguas arriba, el canal principal tiende a un trazado sinuoso (canal superior), conteniendo sedimentos de gravas y arenas en su lecho, lo mismo que las barras laterales activas, completándose con estrechas llanuras fluviomareales. Mantiene un nivel relativamente natural y durante las bajamares, todos los espacios estuarinos quedan al descubierto con la excepción del canal principal, permanentemente inundado, con un carácter cada vez más fluvial, estrecho y encajado en sus llanuras, aguas arriba.

En la barrera de cierre de Somo tuvo lugar un proceso de erosión muy importante a partir de 1988, que se ha acrecentado en el siglo xxI, principalmente desde 2010 y el efecto devastador de los temporales de invierno de 2014 (Borghero, 2015), con la pérdida de sedimento del sistema. Durante los periodos de tormenta, se generaron pasillos de tormenta que en algunas ocasiones conectaron los costados expuesto y protegido en el ápice de la barrera (punta Rabiosa). Otro factor negativo fue la rotura de infraestructuras urbanas y terrazas en edificios que se construyeron indebidamente sobre el sector del campo dunar anexo a la localidad de Somo. En definitiva, se ha calculado que la evolución de la barrera confinante desde el fotograma de 1945 ha consistido en una migración hacia el oeste de $508 \mathrm{~m}$, aproximadamente, y un retroceso de $\mathrm{N}$ a $S$ variable entre $70 \mathrm{~m}$ y $140 \mathrm{~m}$.

\section{Interpretación y discusión}

La existencia de dos grandes cuencas hidrográficas de carácter cordillerano, muy próximas entre sí, situadas algo al O de la bahía de Santander, las del Saja-Besaya y Pas con superficies de cuenca de 966,67 $\mathrm{km}^{2}$ y $620,40 \mathrm{~km}^{2}$ y caudales medios anuales de $36,25 \mathrm{~m}^{3} / \mathrm{s}$ y $16,03 \mathrm{~m}^{3} / \mathrm{s}$, respectivamente (Ugarte Hernández de la Torre et al., 2006), permite inferir que han sido suministradoras netas a este conjunto de Santander de gran parte de las fracciones arenosas y limosas de naturaleza siliciclástica. También el río Miera, que drena al subsistema de Cubas, posee una cabecera glaciada con depósitos (Serrano et al.,
2013) y tramos de afluentes que atraviesan areniscas siliciclásticas y calcarenitas, que aportaron sólidos por tracción al borde costero. Estos componentes de cuarzo, junto con los carbonatados producidos por organismos costeros (bioclastos), en porcentajes promediados de $44,58 \%$ de $\mathrm{CaCO}_{3}$ en el ámbito mareal rocoso (Flor et al., 1982), constituyen los sedimentos de las facies arenosas desarrolladas en las unidades morfosedimentarias y dinámicas externas de la bahía.

Numerosos estudios avalan la trayectoria dinamo-sedimentaria de los sedimentos fluviales en el mar Cantábrico con un transporte persistente hacia el $\mathrm{E}$, coincidente con los oleajes dominantes del NO (Flor, 1978) y la misma desviación por el efecto de Coriolis. Debido a esto último, las plumas de cargas en suspensión durante avenidas se desplazan desde las desembocaduras de grandes ríos hacia el E, incluso con intensos oleajes del NE (Flor y Flor-Blanco, 2014a).

El nivel del mar, como factor que actúa a largo plazo, muestra signos evidentes de una elevación con una tasa de 1,9 mm/año a lo largo del último siglo (Church y White, 2006). En el mar Cantábrico ha sido cuantificado en cifras variables según el criterio utilizado; así, mediante los análisis de datos del mareógrafo de Santander, Chust et al. (2009) lo cifran en 2,08 \pm 0,33 mm/año para el periodo 1943-2004, mientras que García et al. (2012) lo estiman en 2,38 $\mathrm{mm}$ /ańo; por su parte, mediante los contenidos micropaleontológicos y la datación de sondeos verticales en algunos estuarios vascos, García-Artola et al. (2015) calculan una tasa $1,7 \pm 0,2 \mathrm{~mm} /$ año durante el siglo Xx. Respecto a este factor, su repercusión en las áreas costeras provoca efectos como un incremento de las inundaciones, más aún si son costas bajas, y mayor erosión en playas, dunas y acantilados, afectando a la integridad de las infraestructuras y alterando los ecosistemas, como son los casos de marismas y humedales que se inundan y salinizan (EPA, 2010).

Obviamente, los temporales de oleaje constituyen los factores dinámicos ejecutores de los procesos mencionados que se incrementan si coinciden pleamares vivas (Carter, 1991), circunstancias que se produjeron conjuntamente en la costa asturiana con 
gran intensidad (Flor et al., 2014) y cantábrica en general. Pero es la elevación del nivel del mar y la pérdida de sedimentos por erosión natural y/o dragados en los sistemas costeros los condicionantes de los desequilibrios dinamo-sedimentarios más importantes en este conjunto estuarino.

La evolución histórica reciente de los desarrollos urbanos y portuarios de la bahía de Santander, estrechamente conectados entre sí, ha desencadenado una reducción de los espacios estuarinos originales. En el subsistema de Santander se ha producido más intensamente, de modo que, de la superficie original de $43345000 \mathrm{~m}^{2}$, la zona intermareal estaba ocupada por $34765000 \mathrm{~m}^{2} \mathrm{y}$, a finales de los años 70, se redujo hasta $14872000 \mathrm{~m}^{2}$ (Cendrero y Díaz de Terán, 1977).

Rivas y Cendrero (1991) calcularon las áreas reclamadas en la bahía de Santander para periodos desde antes de 1925 hasta 1988 (Tabla 3). El dato anterior a 1925 representa la ocupación masiva, especialmente desde el último tercio del siglo XIX, pero son importantes hasta 1957 y desde 1970 a 1988 en que se llevaron a cabo las mayores desnaturalizaciones, especialmente de marismas, para la construcción del gran puerto de Raos, que garantizara su actividad en los años venideros (http://www.territoriodecantabria.es/Documentos/Contenidos/PEB/ APR_INIC_2014/INFORMACION/1_1_PEB_ EST_TERRITORIALES.PDF).

\begin{tabular}{lcccc}
\hline $\begin{array}{l}\text { periodos } \\
\text { superficie }\end{array}$ & pre-1925 & $1925-1957$ & $1957-1970$ & $1970-1988$ \\
$\left(\times 10^{3} \mathrm{~m}^{2}\right)$ & 15684 & 2172 & 465 & 2863 \\
\hline
\end{tabular}

Tabla 3. Áreas reclamadas (rellenos, desecaciones y aislamientos) en la bahía de Santander en diferentes periodos (tomado de Rivas y Cendrero, 1991).

La reconstrucción cartográfica de las unidades morfosedimentarias en cada hito temporal considerado en este trabajo, reproduce la realidad instantánea del entorno de la bahía, abarcando las variaciones del espacio físico. Se documentan, principalmente, las ocupaciones sucesivas de marismas, masivas en las amplias de Raos y Alday del área occidental por detrás de las instalaciones portuarias de Raos, de modo que la mayor parte de esta margen occidental está representada por rellenos y perímetros de muelles rígidos (Fig. 11). También fueron reseñables las desarrolladas en las márgenes de la ría de Boo o del Carmen, y las meridionales de los arroyos de San Salvador-Tijero y arroyos costeros de la ría de Solía, estas últimas con el añadido de haberse colmatado con los materiales procedentes de los lavaderos de hierro, operativos desde el último tercio del xIx hasta bien entrado el siglo xx. Algunas marismas reclamadas son susceptibles de ser recuperadas fácilmente en el futuro, de modo particular en el subsistema del Cubas, pero también en algunos reductos del margen oriental del subsistema de Santander (Fig. 11).

Todo apunta a que las amplias llanuras arenosas del subsistema de Santander tienen un déficit de recepción de sedimento (APS, 2012a), ya que solamente afloran durante bajamares vivas lo que contrasta con los bancales arenosos del subsistema de Cubas, en total continuidad lateral hacia el $\mathrm{E}$, que descubren durante todo tipo de bajamar.

Por otro lado, la gama variada de intervenciones antrópicas en estuarios es sintetizada por Cooper (2003) para el cual han cambiado con el tiempo y difieren de unas localidades a otras. La construcción de ciudades, transformación de estuarios, rellenos de humedales, repoblaciones vegetales en dunas y dragado de puertos y bahías son solamente unos pocos ejemplos de los impactos mayores derivados del aumento de la densidad de población, que tienen una repercusión directa sobre la costa (Perillo y Piccolo, 2011). Las prácticas más habituales en la mayoría de los estuarios del mundo afectan a la desnaturalización o reclamación de terrenos mareales, como consecuencia de los dragados (van Maren et al., 2015), o bien a la modificación de las bocanas (Flor-Blanco et al., 2015a). Tales desnaturalizaciones de áreas intermareales y marismas suelen producir una amplificación de los rangos mareales, incrementan la circulación estuarina y promueven una asimetría mareal con predominancia del papel de las llenantes (Winterwerp et al., 2013).

Los dragados se suelen aplicar para la profundización de los canales de navegación y rectificación de los trazados, en algunos casos mediante diques. Los prismas mareales se reducen haciéndose las mezclas de agua menos saladas lo que repercute en la biota ante esta mayor continentalización, migrando dentro 


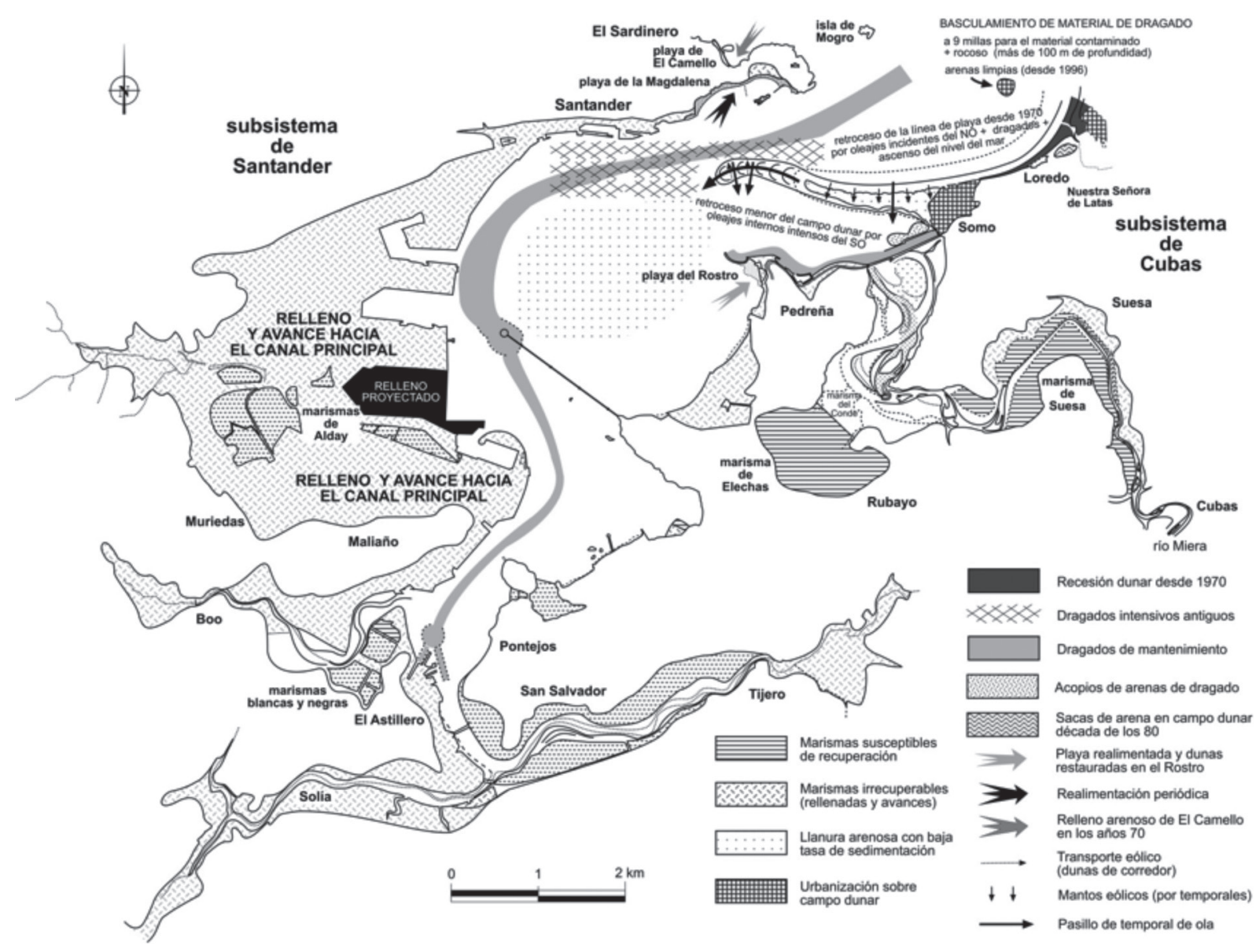

Figura 11. Conjunto de intervenciones reseñables en la bahía de Santander y áreas de influencia en el presente. El relleno proyectado en los muelles de Raos para 2002 (APs, 2012b) se muestra con un recinto en negro.

del estuario o desapareciendo. Otras repercusiones son el incremento de la concentración de sólidos en suspensión y cargas contaminantes de metales y otras sustancias que influyen en las especies vegetales, la infauna o peces migradores. Obviamente, se suscita la problemática de la gestión de dichos materiales de dragado que constituye el aspecto más negativo desde la perspectiva medioambiental (Davis y FitzGerald, 2004), destacando la que interesa a los cambios en las morfologías y volúmenes sedimentarios de sistemas asociados, especialmente a barreras estuarinas con la playa expuesta y las dunas culminantes.

Los dragados efectuados en la bahía de Santander corresponden a proyectos aplicados por etapas de frecuencia y volúmenes extraídos muy irregulares, de modo que en el intervalo $1730-1870$ se contabilizan $16,26 \times 10^{6} \mathrm{~m}^{3}$ y entre 1870 y 1960 un total de $13,85 \times 10^{6} \mathrm{~m}^{3}$ (Losada et al., 1990). Los últimos 35 años del siglo XIx fueron cruciales por cuanto se eliminaron los bajos arenosos de la bocana y bahía (barra de desembocadura y delta mareal de flujo) y se profundizó el canal principal como vía segura de navegación. En esta última década del presente siglo XXI, los dragados fueron del orden de $100000 \mathrm{~m}^{3} /$ año de arena. El canal principal del subsistema de Cubas en la bahía externa, cuya configuración ha cambiado en el intervalo estudiado, se ha fijado definitivamente como de canal de navegación mediante dragados (Fig. 11).

Desde 1996, las arenas limpias de dragado se basculan en el costado oriental sumergido de la playa de Loredo, mientras que las contaminadas se eliminan a 9 millas mar afuera (Fig. 11). Consecuentemente, se evita parcialmente la alarmante pérdida de sedimen- 
to que están adquiriendo los sistemas playa/duna de El Puntal, Somo y Loredo (Sanjosé et al., 2014; Borghero, 2015) y mitigar así los efectos de la subida del nivel de mar y de los fuertes temporales que van a seguir actuando en todo el litoral cantábrico, tal y como se lleva a cabo en otras zonas como Villaviciosa (Flor et al., 2015) o San Vicente de la Barquera (Flor-Blanco et al., 2015b).

Por último, en el primer quinquenio de esta década, se ha materializado un proyecto de dragados de mantenimiento desde 2010 a 2014, ambos inclusive, pero en 2010 y 2011 no se produjo actividad alguna. Para el futuro inmediato, se planifica dragar 6 millones de metros cúbicos desde el muelle $S$ de Raos, incluyendo el canal de navegación hasta la franja exterior sobre la vertical SE de la isla de Mogro (APS, 2012b), a través de un proyecto de 2015-2019. Esta actividad de dragados, cuyos productos sedimentarios se eliminan afuera del sistema playa/dunas, tiene buenos ejemplos en otros puertos cantábricos como el carbonero de San Esteban de Pravia, ubicado en la bahía del estuario del Nalón, que fue sometido a dragados intensivos a lo largo del primer tercio del siglo xx (Flor y Flor Blanco, 2009); desencadenaron un retroceso generalizado de hasta $50 \mathrm{~m}$ en el frente dunar de la playa de Bayas situada justo al E de la desembocadura (Flor-Blanco et al., 2013) hasta $3,75 \mathrm{~km}$ al NE. También se certifica en Salinas-El Espartal (Flor-Blanco et al., 2013), perteneciente a la barrera confinante de estuario de Avilés, debido a la profundización y ensanchamiento del canal de navegación.

Las ocupaciones de los espacios estuarinos han reducido el prisma mareal y se han puesto en relación con los cambios sustanciales en la morfología de la espiga de Somo-El Puntal (Medellín et al., 2009), incluida la migración hacia el $\mathrm{O}$ y los dragados intensivos. Esta tendencia produce el estrechamiento de la bocana y puede ser parcialmente responsable de la erosión de las playas estuarinas, que requieren una realimentación periódica después de cada temporal fuerte de oleaje (Fig. 11).

\section{Conclusiones}

La bahía de Santander está constituida por dos subsistemas estuarinos, el occidental de mayor ampli- tud (Santander, propiamente dicho) cuya margen occidental está muy alterada por rellenos urbanos y portuarios y que ha sido sometido a dragados, en algunas etapas, intensivos. El subsistema oriental de Cubas, cuya bahía arenosa se subdivide en dos franjas externa e interna, se mantiene relativamente natural, lo mismo que las llanuras mareales, aunque se desnaturalizaron, fundamentalmente, marismas y se han rigidizado algunos bordes con rellenos artificiales. Se calcula que el perímetro de la bahía actual, incluidos ambos subsistemas, es de $74,12 \mathrm{~km}$, de los cuales $38,56 \mathrm{~km}$ son naturales y $35,56 \mathrm{~km}$ de carácter rígido.

Con el objeto de deducir la configuración superficial original, se cartografiaron en detalle las grandes formas arenosas antiguas del complejo de desembocadura: paso y barra de desembocadura y franja occidental de la bahía: canal principal y delta mareal de flujo, que fueron eliminadas a finales del siglo XIX por dragados intensivos. Desde los registros de 1956 hasta 2015, se ha llevado a cabo el seguimiento de las superficies desnaturalizadas, delimitándose las unidades morfosedimentarias activas más importantes de ambos subsistemas.

El subsistema de Santander mantiene en buen estado la extensa llanura arenosa $\left(5,65 \times 10^{6} \mathrm{~m}^{2}\right)$, colonizada, en parte por matas algales en la franja interna, y en otros sectores externos con predominio de Zostera spp. No obstante, muestra un carácter sedimentario deficitario ya que solamente descubre unos centímetros durante bajamares vivas, en contraste con las equilibradas dinámica y sedimentariamente del de Cubas. En el caso del subsistema de Cubas, se conservan amplios bancales arenosos muy vegetados y un delta mareal de flujo, incluyendo barras de meandro en el estuario interno. Algunos espacios de antiguas marismas pueden ser recuperados sin grandes obras, lo que contribuirá al incremento del prisma mareal, los efectos positivos derivados de la mayor aportación de nutrientes a la costa y la mejora del patrimonio estuarino.

Los dragados continuados e intensos se han dejado sentir en un retroceso de la playa de Somo-Loredo y sobre la barrera de cierre de Somo-El Puntal. Esta última ha experimentado un crecimiento longitudinal de $508 \mathrm{~m}$ hacia el $\mathrm{O}$, con el consiguiente desplaza- 
miento del paso de desembocadura hacia el interior, y la anchura se ha reducido de forma variable desde $70 \mathrm{~m}$ a $140 \mathrm{~m}$, como máximo.

Los resultados de este trabajo forman parte de un proyecto de investigación en curso más amplio que pretende actualizar y mejorar los datos de las superficies transformadas hasta fechas recientes, así como de las unidades morfosedimentarias y dinámicas de ambos subsistemas, utilizando herramientas de SIG. Por otra parte, la correlación de los volúmenes de dragado en las sucesivas etapas del desarrollo portuario y la evolución de la espiga de Somo, junto con los retrocesos de la playa de Somo-Loredo, añadirá nuevos conocimientos para prevenir el futuro de esta amplia playa arenosa.

\section{Agradecimientos}

Al Servicio de Cartografía del Gobierno de Cantabria por haber proporcionado los diferentes juegos de fotografías, las ortofotografías y los planos topográficos de la zona de estudio. También hay que mostrar nuestro agradecimiento a la labor de ambos revisores, puesto que los comentarios sugeridos han servido para mejorar el artículo.

\section{Bibliografía}

Aps (2012a): Derrotero del Puerto de Santander. Autoridad Portuaria de Santander. Ministerio de Fomento. 22 pp. http://www.puertosantander.es/docDerrotero/derrotero.pdf.

Aps (2012b): Informe de sostenibilidad ambiental del Plan Director de Infraestructuras del Puerto de Santander 2012-2022. Autoridad Portuaria de Santander. 12 Capítulos. 4 Anejos. IH Cantabria. http://www. puertosantander.es/cas/sostenibilidad.html.

Arévalo, A. y del Campo, B. (1843): Plano de la ría y puerto de Santander levantado en 1840. Escala 1:22.000. Corregido y adicionado en 1874. Dirección de Hidrografía. Madrid.

http://bibliotecavirtualdefensa.es/BVMDefensa/ i18n/consulta/registro.cmd?id=7065.
Borghero, C. (2015): Study of morphological evolution of dune fields in Cantabria (N. Spain) during the Anthropocene. Degree Project E1. Department of Earth Sciences. Universidad de Upsala, Suecia.

http://www.diva-portal.org/s mash/get/ diva2:848962/FULLTEXT01.pdf.

Carter, R. W. G. (1991): Near-future sea level impacts on coastal dune landscapes. SPB Academic Publishing bv, The Hague. Landscape Ecology, 6 (1/2): 29-39.

Cearreta, A., Monge-Ganuzas, M. e Iriarte, E. (2008): Consequences of estuarine sand dredging and dumping on the Urdaibai Reserve of the Biosphere (Bay of Biscay): the case of the «Mundaka left wave». Journal of Iberian Geology, 34 (2): 215-234.

Cendrero, A. y Díaz de Terán, J. R. (1977): Caracterización cuantitativa del desarrollo histórico del relleno de la bahía de Santander; un proceso natural activado por el hombre. Revista de Obras Públicas, 124 (3150): 797-808.

Church, J. A. y White, N. J. (2006): A 20th century acceleration in global sea-level rise. Geophysical Research Letters, 33: L01602, doi:10.1029/ 2005 GL024826.

Chust, G., Borja, Á, Liria, P., Galparsoro, I., Marcos, M., Caballero, A. y Castro, R. (2009): Human impacts overwhelm the effects of sea-level rise on Basque coastal habitats ( $\mathrm{N}$ Spain) between 1954 and 2004. Estuarine, Coastal and Shelf Science, 84: 453-462.

Cooper, J. A. G. (2003): Anthropogenic impacts on estuaries, en Isla, F. I. (Ed.). Coastal zones, estuaries. Encyclopedia of Life Support Systems (EOLSS). Oxford, UK, unEsCo, EOLSS Publishers, 246 p.

Cueto Alonso, G. J. (2006): La minería del hierro en la bahía de Santander, 1841-1936: un estudio de Geografía Histórica. Consejería de Medio Ambiente del Gobierno de Cantabria (CIMA), 433 p.

Dantín Cereceda, J. (1917): Evolución morfológica de la bahía de Santander. Trabajos del Museo Nacional de Ciencias Naturales, Serie Geológica, 20, 43 p. 
Davis Jr, R. y Fitzgerald, D. M. (2004): Human interaction with coastal dynamic. Chapter 21. Beaches and Coasts. Blackwell Publishing: 381-404.

Dmac (2012). Directiva Marco del Agua en Cantabria. Subdirección General de Aguas. Consejería de Medio Ambiente del Gobierno de Cantabria.

http://dma.medioambientecantabria.es/estudios/ma_ superficiales/rios/caracterizacion/anejo7_miera.pdf).

Echavarri, B., Juanes, J. A., Puente, A, GarCía-Castrillo, G. y Morante, L. (2007): Seguimiento ambiental del saneamiento integral de la Bahía de Santander: alcance y primeros resultados. Ingeniería del Agua, 14: 37-46.

Epa-U. S. Environmental Protection Agency (2010). Climate change indicators in the United States, EPA 430-R-1-007. www.epa.gov/climatechange/indicators.html.

Falqués, A. Medellín, G. Medina, R. GonzáLEz, M. Ávila, M. (2006): Testing high angle waves instability on a low energy beach. Proceedings of the ASCE American Society of Civil Engineers, Conference 30, 3, San Diego, 2668-2678.

Ferrer Torío, R. y Ruiz Bedia, M. a L. (1991): Los accesos por carretera a Santander desde la zona oriental de la region: Evolución histórica e importancia de los puentes sobre la ría de Solía. Revista de Obras Públicas, 138 (3308): 23-33.

Flemming, B. W., Delafontaine, M. T. y LieBeZeit, G. (eds.) (2000): Muddy coast dynamics and resource management. Proceedings in Marine Science, 2, Elsevier, Amsterdam.

FLOR, G. (1978): Relación entre la distribución de sedimentos y la circulción costera en la región del Cabo Peñas. Trabajos de Geología, 10: 183-194.

Flor, G. y Flor-Blanco, G. (2009): Aspectos geomorfológicos del tramo inferior del estuario de Villaviciosa (Asturias) en relación con su evolución histórica. Revista de la Sociedad Geológica de España, 22: 123-136.
Flor, G. y Flor-Blanco, G. (2014a): Subsistemas estuarinos de la bahía de Santander (Cantabria, $\mathrm{N}$ de España), en Schnabel, S. y Gómez, Á. (eds.): Actas. Avances de la Geomorfología en España 2012-2014. XIII Reunión Nacional de Geomorfología, Cáceres: 568-571.

Flor, G. y Flor-Blanco, G. (2014b): Raised beaches in the Cantabrian coast, en Gutiérrez, F. y Gutiérrez, M. (eds.): Landscapes and Landforms of Spain, Springer: 239-248.

Flor, G., Llera, E. M. a y Ortea, J.A. (1982): Los carbonatos biogénicos de los sedimentos de las playas arenosas de Asturias y Cantabria: su origen y significado dinámico. Cuadernos del CRINAS, 2, 77 p.

Flor, G., Flor-Blanco, G. y Flores-Soriano, C. (2014): Cambios ambientales por los temporales de invierno de 2014 en la costa asturiana (NO de España). Trabajos de Geología, 34: 97-123.

Flor, G., Flor-Blanco, G. y Rey, J. (2015): Dynamics and morpho-sedimentary interactions in the lower mesotidal estuary of Villaviciosa (NW Spain): A management dredging model. Geologica Acta, 13(2): 107-121.

Flor-Blanco, G. (2007): Características morfosedimentarias y dinámicas y evolución ambiental de los estuarios de Tina Mayor, Tina Menor y San Vicente de la Barquera (Costa occidental de Cantabria). Tesis Doctoral, Universidad de Oviedo, 477 p.

Flor-Blanco, G., Flor, G. y Pando, L. (2013): Evolution of the Salinas-El Espartal and Xagó beach/dune systems in north-western Spain over recent decades: evidence for responses to natural processes and anthropogenic interventions. Geo-Marine Letters, 33: 143-157.

Flor-Blanco, G., Pando, L., Morales, J. A. y FLOR, G. (2015a): Evolution of beach-dune fields systems following the construction of jetties in estuarine mouths (Cantabrian coast, NW Spain). Environmental Earth Sciences, 73: 1317-1330.

Flor-Blanco, G., Flor, G., Pando, L. A. y AbanaDES, J. (2015b): Morphodynamics, sediments and 
evolution of the outer portions of the San Vicente de la Barquera estuary (Cantabria, NW Spain), with a focus on anthropogenic influences. Geologica Acta, 13 (4): 279-296.

García, M. J., Tel, E. y Molinero, J. (2012): Sea-level variations on the north and northwest coasts of Spain. ICES Journal of Marine Science, 69: 720-727.

García-Artola, A., Cearreta, A. y Leorri, E. (2015): Relative sea-level changes in the Basque coast (northern Spain, Bay of Biscay) during the Holocene and Anthropocene: The Urdaibai estuary case. Quaternary International, 364: 172-180.

González Urruela, E. (2001). De los tajos a los embarcaderos. La construcción de los espacios de la minería del hierro en Vizcaya y Cantabria (1860-1914). Editorial Ariel Practicum, 316 p.

Halouani, N., Fathallah, S. y Moncef, G. (2012): Beach and nearshore morphodynamic changes of the Tabarka coast, Northwest of Tunisia. Arabian Journal for Science and Engineering, 38 (7): 1851-1860.

Haupt, L. M. (1888): Jetties for improving estuaries. Journal Franklin Institute, 125: 306-313.

Hellín Medina, J. (2011): Análisis climatológico del Mar Cantábrico y su influencia en la navegación. Proyecto Trabajo Fin de Carrera. Facultad de Náutica de Barcelona. 105 p.

http://hdl.handle.net/2099.1/7451

Jiménez, M., Castanedo, S., Medina, R. y Camus, P. (2012): A methodology for the classification of estuary restoration areas: A management tool. Ocean and Coastal Management, 69: 231-242.

Lequerica, J. (1878): Plan General del Puerto de Santander. Archivo de la Junta del Puerto de Santander.

López Peláez, J. (2015): Evolución morfosedimentaria e histórica de los estuarios asturianos de Navia, $\mathrm{Na}$ lón, Avilés, Villaviciosa y Ribadesella. Tesis Doctoral, Universidad de Oviedo, 307 p.
Losada, M. Á., Medina, R. y Vidal, C. (1990): El Puntal Somo-Loredo. Evolución histórica, morfodinámica actual y propuesta de plan de actuaciones. Resumen. Informe Interno (inédito). Dirección General de Puertos y Costas, Junta del Puerto de Santander y Demarcación de Costas de Cantabria, 20 p.

Losada, M. Á. Medina, R. Vidal, C. y Roldán, A. (1991): Historical evolution and morphological analysis of "El Puntal" spit, Santander (Spain). Journal of Coastal Research, 7 (3): 711-722.

MARTÍN LATORRE, E. (2010): La producción y evolución de la ciudad de Santander: interpretación desde el mar de un paisaje urbano-portuario: 27-59. http:// www.uib.cat/ggu/docs/Santander.pdf.

Medellín, G., Falqués, A., Medina, R. y GonzáLEZ, M. (2009): Coastline sand wave son a low-energy beach at El Puntal spit, Spain: Linear stability analysis. Journal Geophysical Research, 114: C03022. doi:10.1029/2007JC004426.

Moñino, M., Díaz de Terán, J. R. y Cendrero, A. (1988): Pleistocene sea level changes in Cantabrian Coast, Spain, en Singh, S. y Tiwari, R.C. (eds.): Allahabad Geographical Society, Allahabad, India, Geomorphology and Environmental Management, 351-364.

Moreno-Ventas, X. (1998): Distribución y dinámica del fitoplancton en la Bahia de Santander. Tesis Doctoral, Universidad de Cantabria, 472 p.

National Research Council, Marine Board (1985): Dredging Coastal Ports: An Assessment of the Issues. Marine Board Commission on Engineering and Technical Systems. National Academies Press. Washington D.C., 212 p.

Orense, J. (1875): Plan General de Mejoras del Puerto de Santander, en JOP 1985. Santander. El puerto y su historia. 1785-1985. Bicentenario del Consulado del Mar. Junta del Puerto de Santander. MOpu.

Peñarredonda, J. (1870): Plano del puerto de Santander y proyectos en curso. Dirección de Hidrografía. Madrid. Servicio Geográfico del Ejército (Cartoteca Histórica). 
Pellón, E., Garnier, R. y Medina, R. (2014): Intertidal finger bars at El Puntal, Bay of Santander, Spain: observation and forcing analysis. Earth Surface Dynamics, 2: 349-361.

Perillo, G. M. E. y Piccolo, M. E. (2011): Global variability in estuaries and coastal settings. Treatise on Estuarine and Coastal Science, 1: 7-36.

Pozueta Echavarri, J. (1985): Santander. El puerto y la ciudad en su historia, en JOP 1985. Santander. El puerto y su historia. 1785-1985. Bicentenario del Consulado del Mar, 11-49. Junta del Puerto de Santander. MOPU.

Puente Trueba, A., Ondiviela, B., Echávarri, B., Juanes, J. y García-Castrillo, G. (2004): Las comunidades bentónicas de la bahía de Santander. Locustella, Anuario de la Naturaleza de Cantabria, 2, 58-69. http://www.locustella.org/revista/02/ pdf/02_GR_05_bentonicas_santander.pdf.

Ramírez del Pozo, J., Portero García, J. M., Olivé Davó, A., Martín Alafont, J. M. y AguiLAR Tomás, M. J. (1974): Hoja 35 (Santander), escala 1/50.000. Mapa Geológico de España. Plan Magna. IGME. Madrid.

Rivas Mantecón, M. ${ }^{a}$ V. (2000): Clima y nivel del mar: reconstrucción de las posiciones marinas cuaternarias a través de las evidencias en el litoral cantábrico, en García Codrón, J. C. (coord.): La reconstrucción del clima de época preinstrumental: 179212. Servicio de Publicaciones de la Universidad de Cantabria, Santander.

Rivas, V. y Cendrero, A. (1991): Use of natural and artificial accretion on the north coast of Spain: Historical trends and assessment of some environmental and economic consequences. Journal of Coastal Research, 7 (2): 491-507.

Rodrigue, J. P. (2004): Appropriate models of port governance: lessons from the Port Authority of New York and New Jersey, en Pinder, D. D. y Slacks, B. (eds.): Shipping and Ports in the Twenty-first Century. Globalisation, technological change and the environment, Routledge, 63-81.
Rodríguez-Ramírez, A., Morales, J. A., DelgaDo, I., y Cantano, M. (2008): The impact of man on the morphodynamics of the Huelva coast (SW Spain). Journal of Iberian Geology, 34(2): 313-327.

Sáiz de Omeñaca, J., Ferrer, F., Calatayud Prieto, T., Cifuentes Vega, P., Ortega Valcárcel, J., Sáiz de Omeñaca, G. y Sáiz de Omeñaca, J.A. (1981): Utilización didáctica del medio ambiente (la bahia de Santander). ICE-Universidad de Santander: $240 \mathrm{p}$.

Sanjosé, J. J., Serrano, E., Berenguer, F, GonzÁlez-Trueba, J. J., Gómez-Lende, M., GonzÁlez-García, M. y Guerrero Castro, M. (2014): Evolución histórica y actual de la línea de costa en las playas de Somo y Gerra (Cantabria) mediante fotogrametría aérea y escáner Láser, en Schnabel, S. y Gómez Gutiérrez, Á. (eds.): Avances de la Geomorfología en España 2012-2014. Actas de la XIII Reunión Nacional de Geomorfología, Cáceres: 560-563.

Serrano, E., Gómez Lende, M., González TrueBA, J. J., Turu, V. y Rox, X. (2013): Fluctuaciones glaciares pleistocenas y cronología en las Montañas Pasiegas (Cordillera Cantábrica). Cuaternario y Geomorfología, 27 (1-2): 91-110.

Ugarte Hernández de la Torre, P., Barquín Ortiz, J., Revilla Cortezón, J. A., Álvarez Díaz, C., Puente Trueba, A., García Gómez, A. y Juanes DE la PeÑA, J. A. (2006): Tipificación de las masas de agua fluviales en la vertiente norte de Cantabria. Actas del III Congreso de Ingeniería Civil, Territorio y Medio Ambiente "Agua, Diversidad e Ingenieria": $14 \mathrm{p}$.

http://www.ciccp.es/biblio_digital/Icitema_III/congreso/pdf/010607.pdf.

Van Maren, D. S., van Kessel, T., Cronin, K. y SitToni, L. (2015): The impact of channel deepening and dredging on estuarine sediment concentration. Continental Shelf Research, 95: 1-14.

Winterwerp, J. C., Wang, Z. B., van Braeckel, A., van Holland, G. y Kösters, F. (2013): Man-induced regime shifts in small estuaries - I: a comparison of rivers. Ocean Dynamics, 63 (11-12): 1293-1306. 